\title{
The Impact of the Amazon-Orinoco River Plume on Enthalpy Flux and Air-Sea Interaction within Caribbean Sea Tropical Cyclones
}

\author{
Johna E. Rudzin, Lynn K. SHAY, AND BENJAMIn JAIMES DE LA CRUZ \\ Department of Ocean Sciences, Rosenstiel School of Marine and Atmospheric Science, \\ University of Miami, Miami, Florida
}

(Manuscript received 16 August 2018, in final form 28 December 2018)

\begin{abstract}
The influence of the Amazon-Orinoco River plume in the Caribbean Sea on latent and sensible heat flux (enthalpy flux) and tropical cyclone (TC) intensity is investigated for Hurricanes Ivan (2004), Emily (2005), Dean (2007), and Felix (2007) using dropwindsonde data, satellite sea surface temperature (SST), and the SMARTS climatology. Relationships among enthalpy fluxes, ocean heat content relative to the $26^{\circ} \mathrm{C}$ isotherm depth (OHC), and SST during storm passage are diagnosed. Results indicate that sea surface cooling in the river plume, a low-OHC region, is comparable to that in the warm eddy region, which has high OHC. An isothermal layer heat budget shows that upper-ocean cooling in the river plume can be explained predominantly by sea-to-air heat flux, rather than by entrainment flux from the thermocline. The latter two findings suggest that relatively large upper-ocean stratification in the plume regime limited entrainment cooling, sustaining SST and enthalpy flux. Inspection of atmospheric variables indicates that deep moderate wind shear is prevalent, and equivalent potential temperature is enhanced over the river plume region for most of these storms. Thus, sustained surface fluxes in this region may have provided warm, moist boundary layer conditions, which may have helped these storms to rapidly intensify even over relatively low-OHC waters and moderate shear. These findings are important because several Caribbean Sea TCs, including these cases, have been underforecast with respect to intensity and/or rapid intensifications, yet minimal upperocean observations exist to understand air-sea interaction during TCs in the salinity-stratified AmazonOrinoco plume regime.
\end{abstract}

\section{Introduction}

The Caribbean Sea is a frequent pathway for tropical cyclones (TCs); these storms encounter several different ocean regimes such as the Amazon-Orinoco River plume, the Caribbean Current, the Yucatan Current, and large warm-core eddies (WCEs) that reside in the basin. During the late summer months of the Atlantic hurricane season, sea surface temperature (SST) remains fairly homogeneous throughout the basin (Fig. 1). Yet, ocean heat content relative to the $26^{\circ} \mathrm{C}$ isotherm [OHC; Leipper and Volgenau 1972; Eq. (1)] ranges from $20 \mathrm{~kJ} \mathrm{~cm}^{-2}$ in the plume waters to over $150 \mathrm{~kJ} \mathrm{~cm}^{-2}$ in WCEs (Fig. 1). OHC is the depth-integrated thermal energy from the depth of the $26^{\circ} \mathrm{C}$ (D26) isotherm to the sea surface $(\eta)$, where $T(z)$ is ocean temperature at a specified depth $z, \rho$ is ocean density, and $c_{p}$ is the specific heat capacity of the ocean, $4000 \mathrm{~J} \mathrm{~kg}^{-1}{ }^{\circ} \mathrm{C}^{-1}$. $\mathrm{OHC}$ is a proxy for TC heat potential since it is estimated

Corresponding author: Johna E. Rudzin, jrudzin@rsmas.miami.edu using the $26^{\circ} \mathrm{C}$ isotherm, the threshold conventionally accepted for TC development and maintenance (Palmén 1948):

$$
\mathrm{OHC}=\rho c_{p} \int_{\mathrm{D} 26}^{\eta}[\mathrm{SST}-T(z)] d z
$$

Many studies have shown in other basins how deepocean mixed layers and high $\mathrm{OHC}$ act to reduce SST cooling during TC forcing, since entrainment cooling is less with deep-ocean mixed layers, and sustain air-sea fluxes into the storm (Shay et al. 2000; Lin et al. 2005, 2009, 2013; Shay and Uhlhorn 2008; Jaimes and Shay 2009, 2010; Jaimes et al. 2015). In addition to ocean thermal structure, a few studies have indicated that the upper-ocean salinity stratification within the AmazonOrinoco River plume plays a role in modulating SST during TC passage by reducing the efficiency of upperocean mixing (Wang et al. 2011; Neetu et al. 2012; Balaguru et al. 2012; Grodsky et al. 2012; Vissa et al. 2013; 

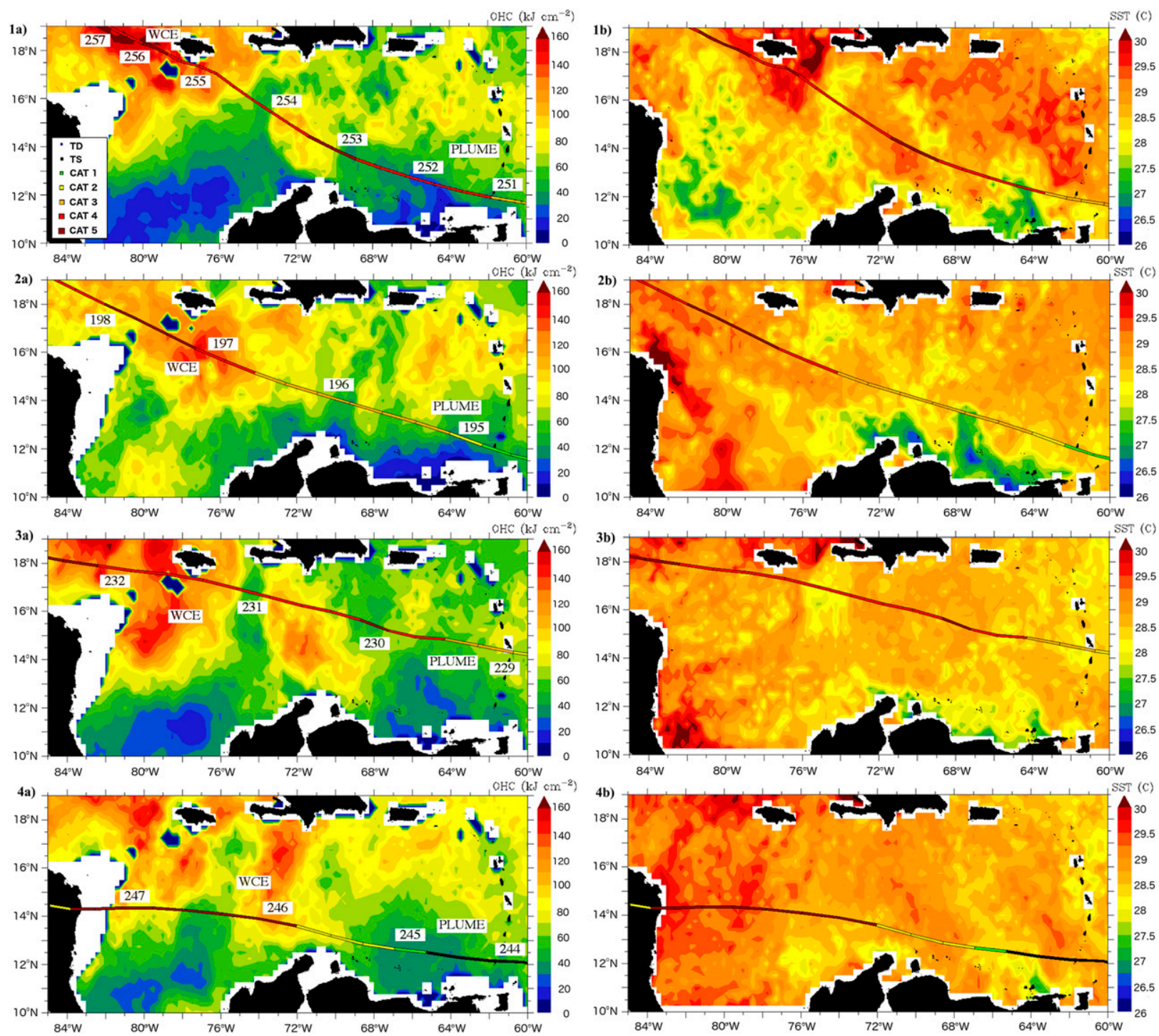

FIG. 1. Tracks of (panels 1a and 1b) Ivan (2004), (panels 2a and 2b) Emily (2005), (panels 3a and 3b) Dean (2007), and (panels 4a and 4b) Felix (2007) over (a) prestorm SMARTS OHC and (b) prestorm GHRSST SST within the Caribbean Sea. Day of year for storm track overlain in (left). Ocean regimes are also indicated.

Reul et al. 2014; Androulidakis et al. 2016; Hernandez et al. 2016; Rudzin et al. 2017; Yan et al. 2017; Rudzin et al. 2018). Increased stability in the isothermal layer (constant ocean temperature layer that is within $0.5^{\circ} \mathrm{C}$ of SST) via salinity stratification is shown using the Brunt-Väisälä frequency in Fig. 2. Rudzin et al. (2017) reported upper-ocean Brunt-Väisälä frequencies within the eastern Caribbean Sea during the Amazon-Orinoco River plume's peak outflow of up to 15 cycles per hour. The freshwater runoff creates a stable ocean surface layer that keeps the ocean mixed layer (constant density layer) fairly shallow ( $\sim 10-20 \mathrm{~m}$; Lentz and Limeburner, 1995; Hu et al. 2004; Rudzin et al. 2017). However, large amounts of incoming solar radiation during the summer act to deepen the isothermal layer, creating a barrier layer between the ocean surface and the thermocline (Sprintall and Tomczak 1992; Pailler et al. 1999; Mignot et al. 2007, 2012). Barrier layers are characterized by a vertical salinity gradient within the isothermal layer and suppress turbulent heat flux from the ocean's thermocline to the sea surface, creating a "barrier" of heat exchange between these layers. However, the isothermal layers that exist within the Amazon-Orinoco River plume are relatively shallow, and $\mathrm{OHC}$ is low, compared to Caribbean Sea warm eddies and the Caribbean Sea warm pool (Fig. 1), signifying this area should experience a relative significant SST cooling during TC passage and reduce air-sea fluxes to the TC. 

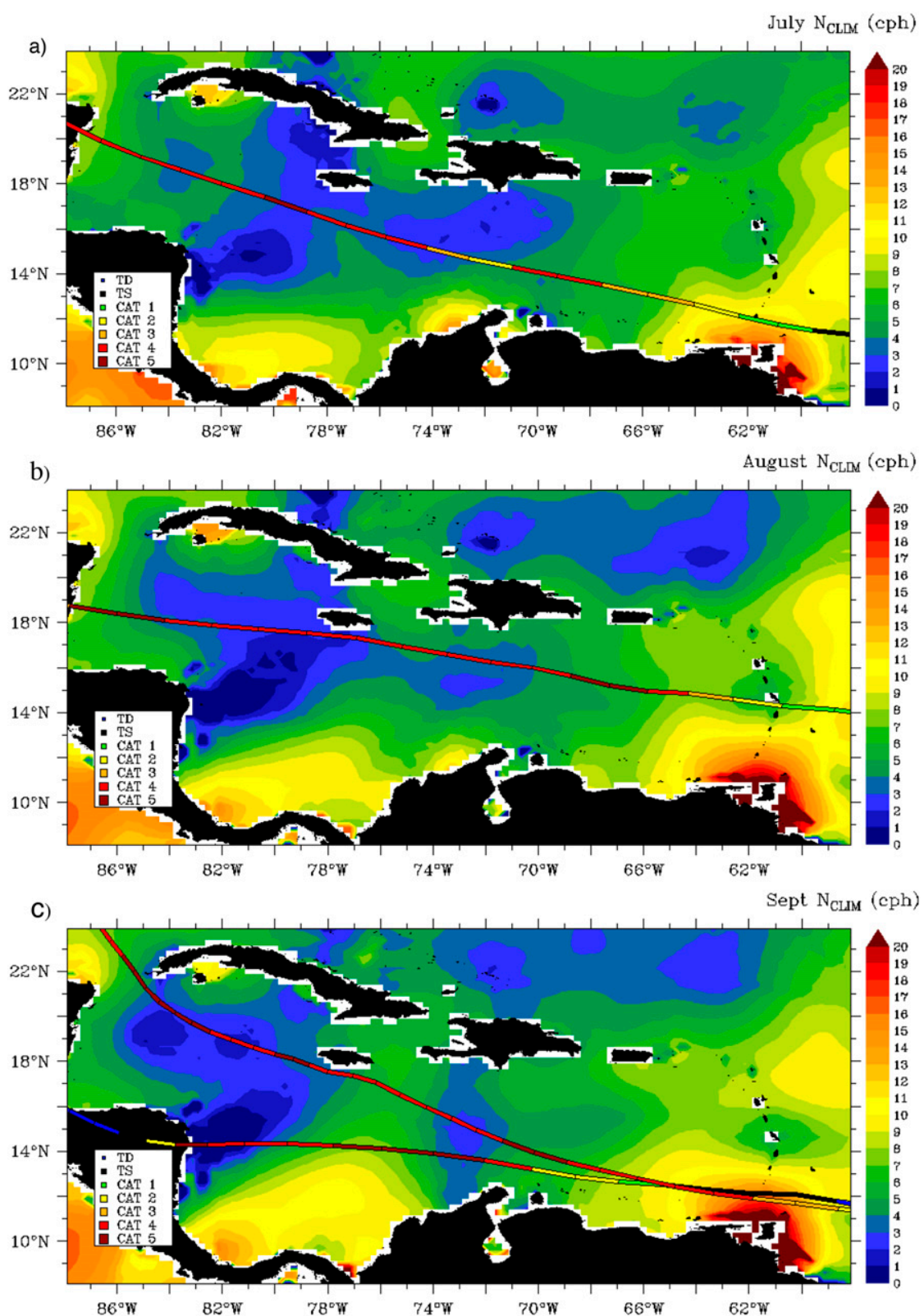

FIG. 2. Monthly climatological Brunt-Väisälä frequency ( $\mathrm{cph}$ ) calculated for the upper $50 \mathrm{~m}$ using World Ocean Atlas 2001 temperature and salinity profiles. (a) July field with Emily (2005) track, (b) August field with Dean (2007) track, and (c) September field with Ivan (2004) and Felix (2007) tracks.

In this study, we investigate air-sea fluxes and ocean response in four of the most intense TC cases in the Caribbean Sea: Hurricane Ivan (2004), Hurricane Emily (2005), Hurricane Dean (2007), and Hurricane Felix (2007). This is the first study, to our knowledge, to investigate the role of the Amazon-Orinoco River plume on air-sea interaction during TC rapid intensification (RI) events. All four TCs pass over both the AmazonOrinoco River plume and a large WCE, and three of the four undergo RI while over the plume. Additionally, all four storms' intensities were underforecast while over the plume (Stewart 2004; Franklin and Brown 2006; Franklin 2008; Beven 2008). The Amazon-Orinoco River plume region is defined as the area between $58^{\circ}$ and $66^{\circ} \mathrm{W}$ with increased Brunt-Väisälä frequency in Fig. 2.

Using these specific storms allows us to compare airsea interaction between low-OHC waters of the plume and high-OHC waters of a warm eddy and to identify the 
significance of the plume on SST response and air-sea fluxes. A key question to address is whether the SST response over the Amazon-Orinoco River plume can sustain comparable sea-to-air enthalpy fluxes as over the WCEs, since previous studies suggest that TC intensification over the plume is related to reduced SST cooling. Prestorm OHC and pre- and poststorm SST tendencies are analyzed with respect to air-sea fluxes to examine the relationship among air-sea exchange, SST, and subsurface ocean thermal structure. An upper-ocean heat budget is estimated to assess which processes are responsible for SST fluctuations and the influence of salinity on SST response. Finally, broadscale atmospheric parameters over the Amazon-Orinoco River plume region for each storm are examined to evaluate if the ocean's influence is apparent in each storm's intensification over this region.

\section{Data}

\section{a. GPS dropwindsondes and sea surface temperature}

Global positioning system dropwindsondes (hereafter dropsondes) from the National Center for Atmospheric Research (NCAR) provide vertical atmospheric profiles of air temperature, wind speed, wind direction, and relative humidity (Hock and Franklin 1999). Real-time data are postprocessed using NCAR's Atmospheric Software Processing Environment (ASPEN) software, which quality controls each dropsonde sounding.

Daily satellite-based blended level 4 SST analyses from the Jet Propulsion Laboratory PODAAC Group for High Resolution Sea Surface Temperature (GHRSST) Level 4 MUR (JPL MUR MEaSUREs Project 2010) are used within the air-sea flux estimations. Satellite SST is used due to the lack of in situ SST observations within the Caribbean Sea during the case studies. This specific product was chosen because it incorporates microwave sensors, which are needed to resolve SST variability in cloudy situations, and because of its high spatial resolution. In-storm SST (SSTin) and 1-day-prestorm SST (SSTpre) are used in this study. SST differences between airborne expendable bathythermographs (AXBTs) and collocated SSTin from GHRSST daily satellite product are estimated for over 400 AXBT Gulf of Mexico deployments (appendix A) to identify differences between in situ observations and this satellite product. Approximately $70 \%$ of SST differences are found within $0.5^{\circ} \mathrm{C}$ (Fig. 3). Zhang et al. (2017) found a bias of $0.62^{\circ} \mathrm{C}$ when they compared 30 AXBT and infrared SST measurements on dropwindsondes in Hurricane Edouard (2014). Given that the bias is larger in Zhang et al. (2017) and that their sample size is much smaller than in this analysis, we feel that the use of this SST product is suitable for the goal of this work,

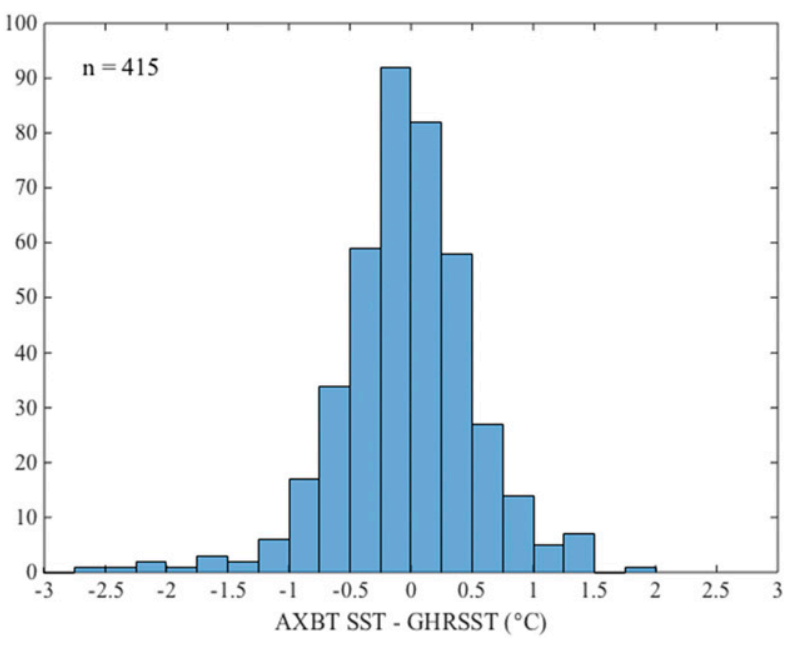

FIG. 3. Histogram of SST difference between the AXBT (data from Upper Ocean Dynamics Laboratory at RSMAS/UM) and the GHRSST SST daily satellite product for 415 AXBT deployments within Hurricanes Frances (2004), Jeanne (2004), Rita (2005), Dennis (2005), Gustav (2008), Ike (2008), and Danny (2009). GHRSST SST was collocated in space and time (same day as AXBT deployment) to estimate difference shown here.

given the lack of in situ SST measurements. Furthermore, the use of SSTin for air-sea flux estimates is also evaluated by comparing air-sea fluxes estimated with SSTpre, 1-daypoststorm SST, and 2-day-poststorm SST to make sure using SSTin for air-sea flux estimates is within the envelope of observed SST variability. Air-sea fluxes using SSTin should fall between those using SSTpre and the two poststorm estimates; Figs. A1-A4 indicate that this is the case.

\section{b. SMARTS}

Daily isotherm depths, isothermal layer depths (ILDs), and $\mathrm{OHC}$ are provided by the Systematically Merged Atlantic Temperature and Salinity Climatology (SMARTS; Meyers et al. 2014). Remote sensing systems SST (Gentemann et al. 2009) is normally used in the SMARTS research product to calculate output fields listed previously. However, since the GHRSST SST product is used to calculate air-sea fluxes, this study uses SMARTS data that have implemented GHRSST SST to calculate output fields.

\section{Calculation of air-sea fluxes}

Dropsonde data are acquired from U.S. Air Force Reconnaissance flights, NOAA WP-3 flights, and NOAA G-IV flights (Table 1). Next, the 10-m variables of wind speed, zonal and meridional wind components, specific humidity, and air temperature are extracted from each profile. Dropsonde locations are then transformed from Cartesian coordinates into a storm-coordinate system. This technique follows Jaimes et al. (2015). 
TABLE 1. Number of research/reconnaissance flights and dropsondes per cluster per storm. Flight-naming convection has month and day of flight (MMDD), aircraft type (A = U.S. Air Force Reserve, N = NOAA G-IV, H and I = NOAA WP-3D), and flight number for the aircraft that day (e.g., 1 = first flight). The number of dropsondes listed is what is used to create cluster flux fields for each cluster for each storm.

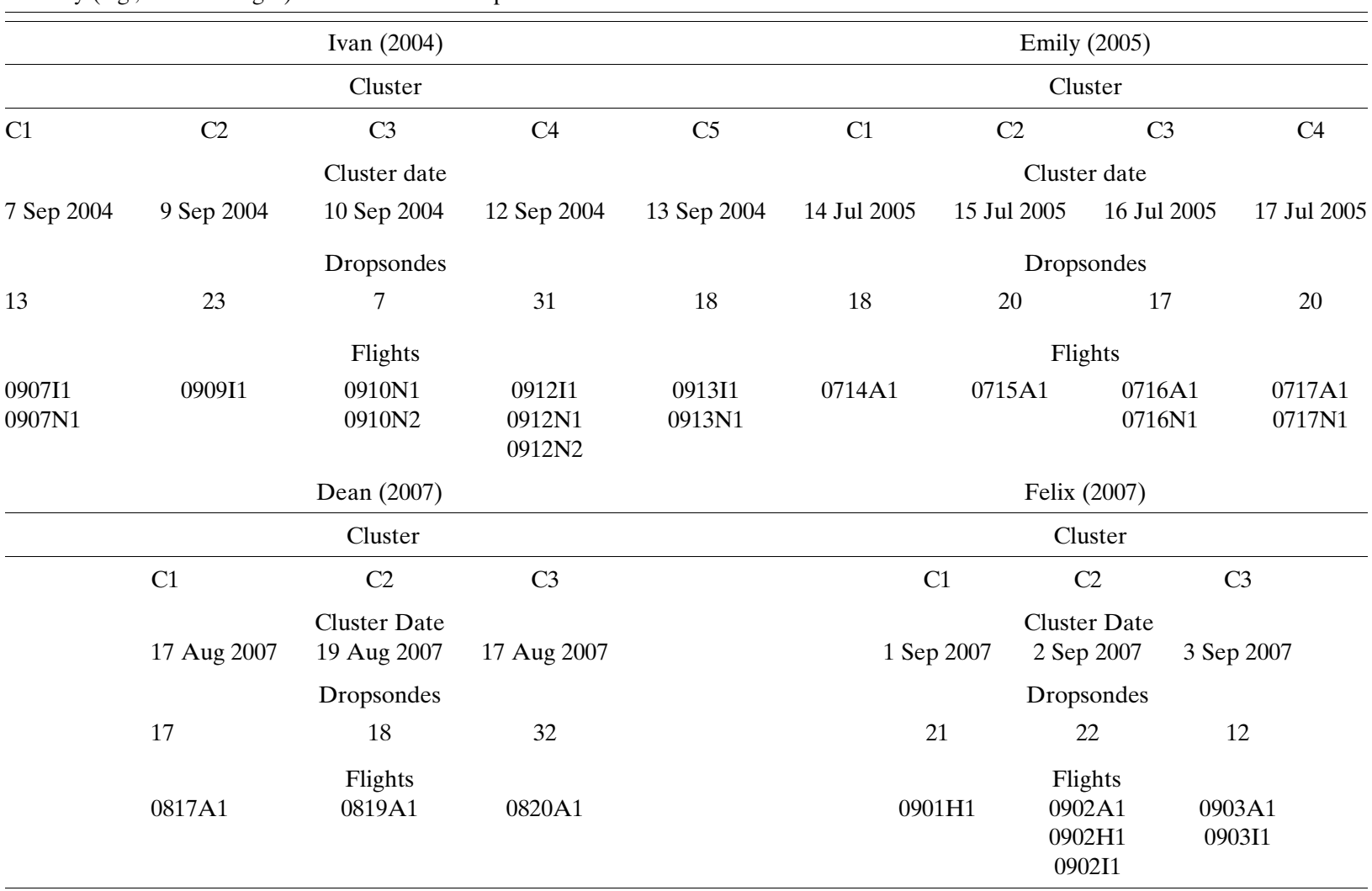

The axes represent the along- and across-track storm fields. The storm-coordinate axis is divided into radials that represent the radius of maximum winds (Rmax) of each storm, where the first radial is $1 \mathrm{Rmax}$ distance and increases outward. This allows comparison between storms of different sizes since horizontal distances are normalized by Rmax. Dropsonde points are then separated into data "clusters," where a cluster represents all the dropsonde data from 1 day during the storm track that are contained within 5 Rmax (Table 1).

\section{Air-sea fluxes}

Air-sea fluxes are estimated using dropsonde data from each cluster. GHRSST SST is extracted for the date and location of each dropsonde within the cluster. Since SST is a daily product, it is chosen for the day of the storm (SSTin). As stated previously, a sensitivity test of flux calculations using different days of SST for the dropsonde locations is conducted to ensure that the flux calculation is within the observed variability in SST (appendix A). The Caribbean Sea's long inertial period $(\sim 48 \mathrm{~h})$ prevents much of the near-inertial shear-induced cooling signal in the daily SST product. Thus, any evolution of SST between SSTpre and SSTin is assumed to be a result of the wind-driven Kraus and Turner (1967) cooling mechanism (i.e., instantaneous wind erosion).

Momentum $\tau$, latent heat $Q_{l}$, sensible heat $Q_{s}$, and enthalpy fluxes $Q_{h}$ are estimated for each dropsonde within a cluster using bulk aerodynamic formulas:

$$
\begin{aligned}
\tau & =\rho_{a} C_{d}\left|U_{10}\right|^{2}, \\
Q_{l} & =\rho_{a} L_{v} C_{q}\left|U_{10}\right|\left(q_{\mathrm{SST}}-q_{\mathrm{A} 10}\right), \\
Q_{s} & =\rho_{a} C_{p} C_{h}\left|U_{10}\right|\left(\mathrm{SST}-T_{\mathrm{A} 10}\right), \\
Q_{h} & =Q_{l}+Q_{s},
\end{aligned}
$$

where $q_{\mathrm{SST}}$ is the saturation specific humidity at SST (assumed to be at $98 \%$ saturation at the SST; Buck 1981), $q_{\mathrm{A} 10}$ is the saturation specific humidity of the air at $10 \mathrm{~m}, \rho_{a}$ is atmospheric density, $L_{v}=2.5 \times 10^{6} \mathrm{~J} \mathrm{~kg}^{-1}$ is the latent heat of vaporization, $c_{p}=1004 \mathrm{~J} \mathrm{~kg} \mathrm{~K}^{-1}$ is the specific heat of air at constant pressure, and $\left|U_{10}\right|$ is wind speed at $10 \mathrm{~m}$ (referred to as $U_{10}$ hereafter). Both $C_{h}$ and $C_{q}$ are assumed to be equal such that $C_{h}=C_{q}=$ $C_{k}$, where coefficients $C_{k}$ and $C_{d}$ are based on field experiments from Powell et al. (2003), Black et al. (2007), and Zhang et al. (2008). 
TABLE 2. Various air-sea parameters for the PLUME and WCE regimes for each storm. Locations of estimates for each regime depicted in Fig. 1.

\begin{tabular}{llcccc}
\hline \multicolumn{1}{c}{ Variable } & Regime & Ivan & Emily & Dean & Felix \\
\hline Maximum $Q_{h}\left(\mathrm{~W} \mathrm{~m}^{-2}\right)$ & PLUME & 1090 & 660 & 790 & 1500 \\
Average $V_{\max }\left(\mathrm{m} \mathrm{s}^{-2}\right)$ & WCE & 1650 & 370 & 815 & 425 \\
& PLUME & 61.7 & 51.4 & 46.3 & 33.4 \\
$\mathrm{SST}_{\text {in }}\left({ }^{\circ} \mathrm{C}\right)$ & WCE & 82.3 & 69.5 & 69.5 & 77.2 \\
\multirow{2}{*}{ Maximum OHC $\left(\mathrm{kJ} \mathrm{cm}^{-2}\right)$} & PLUME & $28.0-29.0$ & 28.5 & $28.0-28.3$ & 28.5 \\
Climatological $N_{\text {ILD }}(\mathrm{cph})$ & WCE & $28.5-30.0$ & 28.5 & $28.0-29.0$ & 29.0 \\
& PLUME & 50 & 60 & 50 & 50 \\
& WCE & 100 & 130 & 100 & 100 \\
& PLUME & 18 & 12 & 8 & 16 \\
\hline
\end{tabular}

\section{Results and discussion}

\section{a. Enthalpy flux with respect to across-track prestorm $O H C$ and $\triangle S S T$}

Storm flights, dropsonde, and cluster information for all four storms are listed in Table 1. Clusters are denoted with "C" followed by cluster number (e.g., C1 for cluster 1). Six-hourly storm fixes from NHC best track data (Landsea et al. 2004) are interpolated to obtain 2-h storm-track locations. Using these locations, acrosstrack OHC and SST fields are created by extracting SMARTS and GHRSST data from \pm 5 Rmax that are perpendicular to the storm track at 2-h intervals. Estimated errors in $Q_{h}$ induced by errors in $U_{10}\left( \pm 2 \mathrm{~m} \mathrm{~s}^{-1}\right.$ from dropsonde measurements) range from \pm 3 to $75 \mathrm{~W} \mathrm{~m}^{-2}$ depending on storm and cluster.

Enthalpy fluxes are compared to SMARTS prestorm OHC (OHCpre), GHRSST in-storm SST (SSTin), and prestorm SST (SSTpre), given that prestorm OHC environment is assumed to dictate the SST response and, thus, affect enthalpy flux. Value ranges of these variables in addition to maximum wind speed from best track $\left(V_{\max }\right)$ and climatological mixed layer $N$ for the different storms and ocean regimes are listed in Table 2. In general, areas of high OHCpre (Figs. 4b-7b) correspond to reduced SST cooling for all four storms (Figs. 4c-7c). This is shown by the small departure between SSTpre and SSTin. However, it is interesting to note that when all four storms are over the AmazonOrinoco River plume region (herein referred to as PLUME), the change in across-track SST from SSTpre (length of blue lines in Figs. 4c-7c) is comparable to that in the higher-OHC warm eddy regions (denoted WCE). Consequently, enthalpy fluxes in the PLUME regime are at least $60 \%$ of that within the WCE regimes for three of the four storms (Figs. 4a-6a), even though $V_{\max }$ differs between these two regimes (Figs. 4d-7d). Enthalpy fluxes in the PLUME regime for Felix only account for one-third of those in the WCE regime
(Fig. 7a). Atmospheric influence on Felix is further investigated in section $4 \mathrm{c}$.

For Ivan, across-track differences between mean SSTin and mean SSTpre in the PLUME range from $-0.5^{\circ}$ to $+0.1^{\circ} \mathrm{C}$ with $\mathrm{OHC} \sim 50 \mathrm{~kJ} \mathrm{~cm}^{-2}$, whereas these differences range from $-0.7^{\circ}$ to $0.0^{\circ} \mathrm{C}$ in the WCE areas with $\mathrm{OHC} \sim 100 \mathrm{~kJ} \mathrm{~cm}^{-2}$ (Figs. $4 \mathrm{~b}, \mathrm{c}$ ). SSTs are approximately $28^{\circ} \mathrm{C}$ in the PLUME regime, whereas they are $30^{\circ} \mathrm{C}$ in the WCE regime (Fig. 4c). Mean enthalpy flux within 5 Rmax in the PLUME is roughly $60 \%$ of that within the WCE areas, with $Q_{h}$ ranging from 230 to $1090 \mathrm{~W} \mathrm{~m}^{-2}$ in the PLUME regime and from 350 to $1650 \mathrm{~W} \mathrm{~m}^{-2}$ in the WCE regime (Fig. 4a). For Emily, across-track differences between SSTin and SSTpre in the PLUME range from $-0.3^{\circ}$ to $+0.1^{\circ} \mathrm{C}$ with $\mathrm{OHC}$ values of $30-60 \mathrm{~kJ} \mathrm{~cm}^{-2}$, whereas these differences range from $-0.4^{\circ}$ to $+0.3^{\circ} \mathrm{C}$ in the WCE areas with $\mathrm{OHC}$ values of $90-130 \mathrm{~kJ} \mathrm{~cm}^{-2}$ (Figs. 5b,c). In-storm SST values are approximately the same between the PLUME and WCE regimes as Emily passed through. Consequently, this leads to $Q_{h}$ values of $60-660 \mathrm{~kJ} \mathrm{~cm}^{-2}$ in the PLUME regime and $140-370 \mathrm{~kJ} \mathrm{~cm}^{-2}$ in the WCE regime (Fig. 5a). This equates to mean enthalpy flux within 5 Rmax in the PLUME being roughly $88 \%$ of that within the WCE. For Dean, across-track differences between mean SSTin and mean SSTpre in the PLUME regime range from $-0.2^{\circ}$ to $0.0^{\circ} \mathrm{C}$ with $\mathrm{OHC} \sim 50 \mathrm{~kJ} \mathrm{~cm}^{-2}$, whereas these differences are approximately $-0.2^{\circ} \mathrm{C}$ in the WCE areas with $\mathrm{OHC}$ values of $90-100 \mathrm{~kJ} \mathrm{~cm}^{-2}$ (Figs. 6b,c). Like the other storms, SSTin is approximately $28^{\circ} \mathrm{C}$ in the PLUME, with values up to $1^{\circ} \mathrm{C}$ higher in the WCE regime. Thus, enthalpy fluxes were very similar in both PLUME and WCE regimes, with values of $15-790$ and $15-815 \mathrm{~kJ} \mathrm{~cm}^{-2}$ in each regime, respectively (Fig. 6a), with the mean value within $5 \mathrm{Rmax}$ in the PLUME being within $98 \%$ of that in the WCE regime.

In Felix, across-track differences between mean SSTin and mean SSTpre are equivalent for both PLUME and WCE regimes $\left(\sim-0.2^{\circ} \mathrm{C}\right)$, but $\mathrm{OHC}$ values 

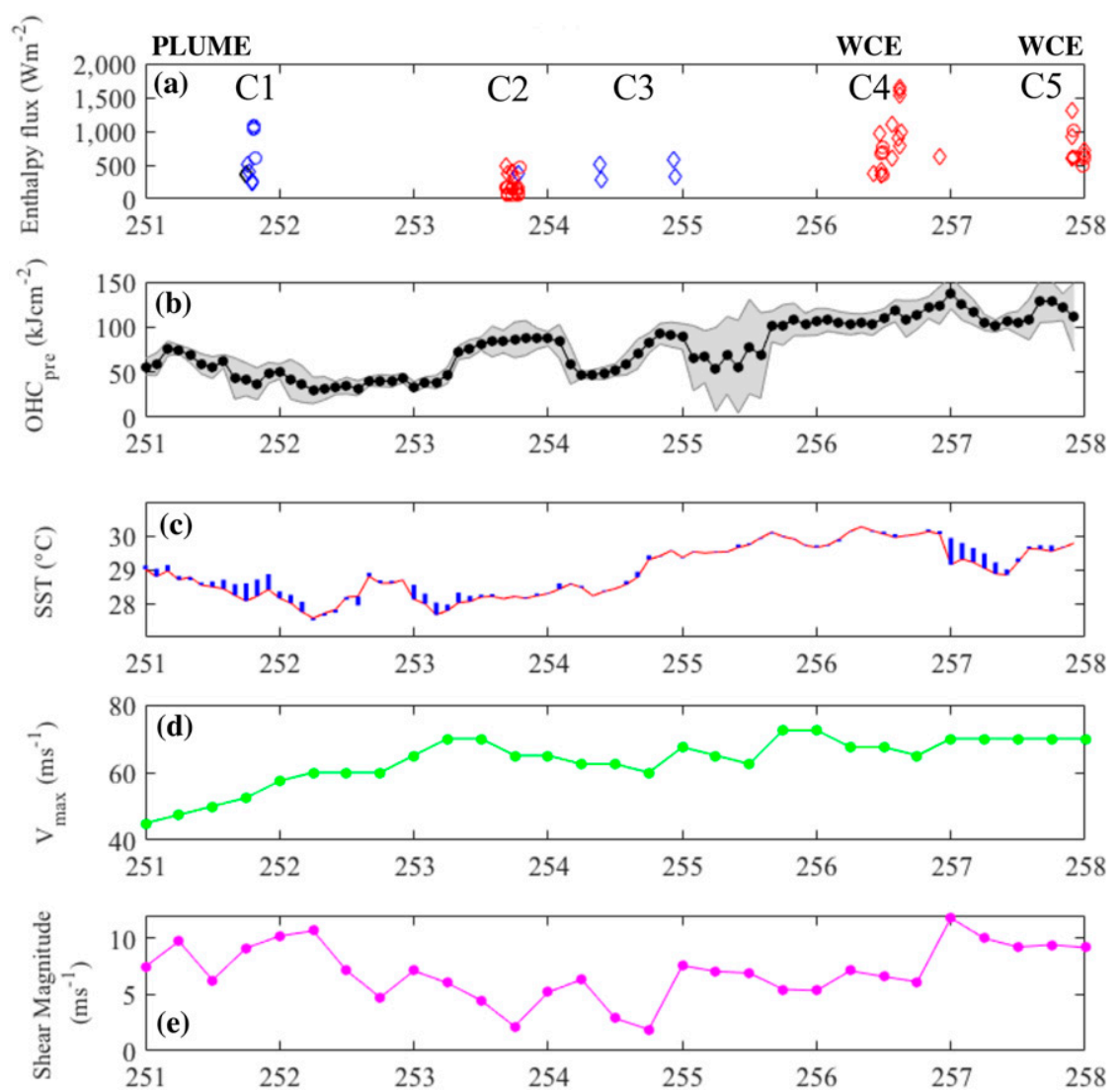

FIG. 4. (a) Enthalpy fluxes estimated from dropsondes along the storm track are plotted with respect to when dropsondes were deployed, also indicated by cluster number (C1-C5). Respective ocean regime (PLUME, WCE) is also indicated. Day of year along track and ocean regime can be visualized in Fig. 1. Dropsondes deployed within 2 Rmax are indicated by circles, whereas dropsondes outside of $2 \mathrm{Rmax}$ are indicated by diamonds. Enthalpy fluxes are color coded with respect to underlying OHCpre, where red markers indicate dropsondes were deployed in areas where OHCpre $\geq 60 \mathrm{~kJ} \mathrm{~cm}^{-2}$, and blue markers indicate dropsondes were deployed in areas were OHCpre $<60 \mathrm{~kJ} \mathrm{~cm}^{-2}$. Black marker indicates OHCpre data were not available for that location. (b) Mean across-track OHCpre (black line) \pm 1 std dev (shading) along Ivan's track. (c) Mean across-track SSTin (red) along Ivan's track. Blue bars indicate the prestorm SST (SSTpre) such that the departure from prestorm to in-storm SST (SST cooling/ warming) can be visualized at 2-h intervals. (d) Maximum wind speed from NHC best track at 6-h intervals. (e) The 850-200-hPa deep layer wind shear magnitude from the SHIPS database (DeMaria and Kaplan 1994) at 6-h intervals.

differ between regimes by $10-50 \mathrm{~kJ} \mathrm{~cm}^{-2}$ (Figs. $7 \mathrm{~b}, \mathrm{c}$ ). The $Q_{h}$ values within 5 Rmax in the PLUME are only $30 \%$ of those within the WCE regime (Fig. 7a). Since this cannot be explained by SST or OHC differences, Felix's intensity is further examined with respect to atmospheric favorability (deep layer wind shear and boundary layer equivalent potential temperature) in section $4 \mathrm{c}$.

These comparisons in $Q_{h}$, OHCpre, and SST changes between the PLUME and WCE regimes signify that something other than upper-ocean thermal structure (as measured by $\mathrm{OHC}$ ) is causing reduced SST cooling in the PLUME region. Is the salinity stratification within the PLUME causing reduced SST cooling response, sustaining enthalpy fluxes that are comparable to deeper isothermal layer and higher-OHC regions? A breakdown of the full isothermal heat budget should not only indicate this, but also point out if entrainment heat flux is less over the PLUME, compared to other regions, signifying that the reduced wind speeds over the PLUME (Figs. $4 \mathrm{~d}-7 \mathrm{~d}$ ) are not the reason for the SST cooling signature observed.

\section{b. Isothermal layer heat budget}

A simple isothermal layer heat budget is calculated for clusters over the Amazon-Orinoco plume region 

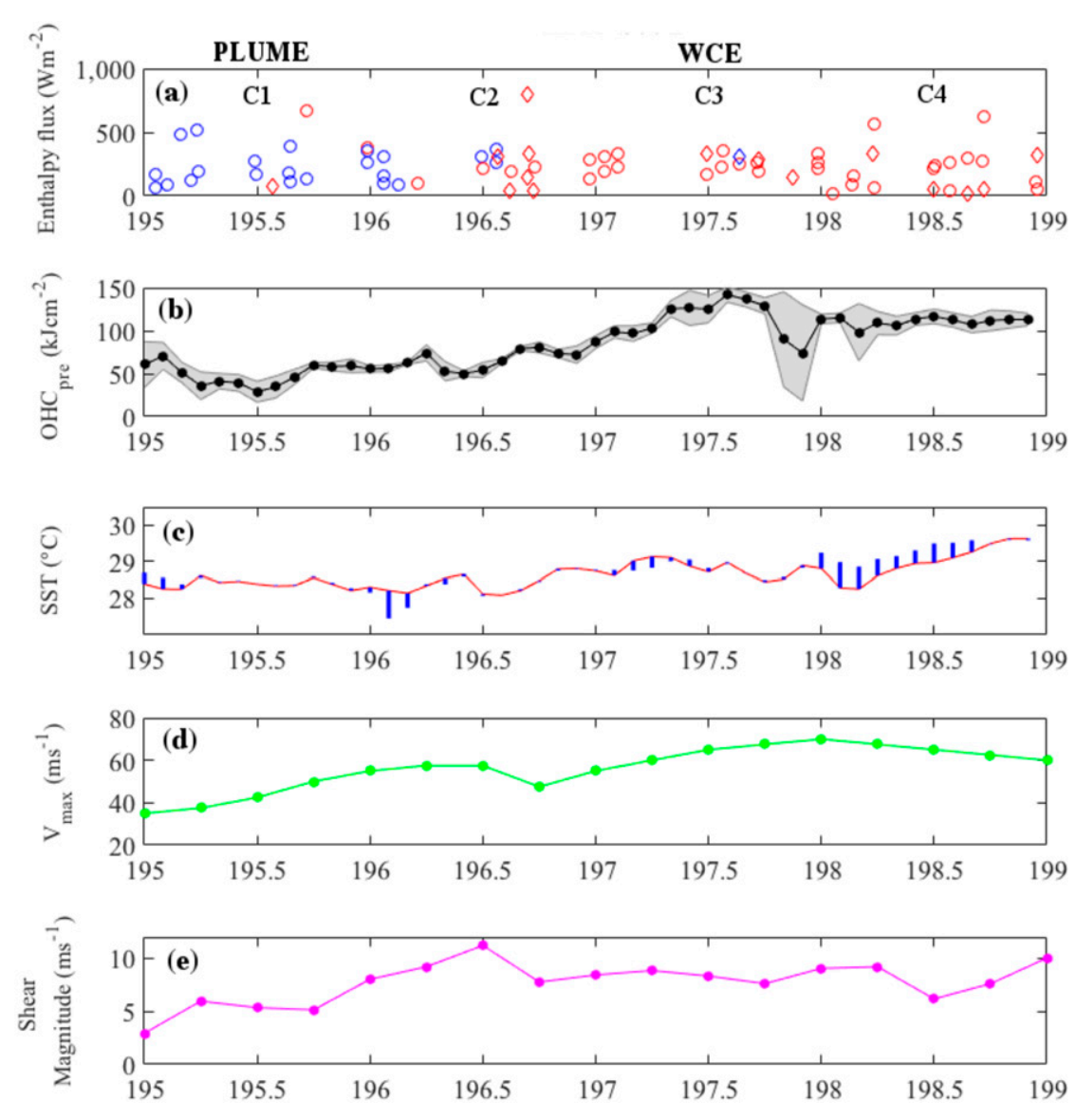

FIG. 5. As in Fig. 4, but for Hurricane Emily (2005).

(C1) of Ivan, Emily, Dean, and Felix to examine if upper-ocean salinity stratification is helping to reduce SST cooling in the Amazon-Orinoco River plume regime. The heat budget is calculated within the isothermal layer, given that the true density ocean mixed layer is very shallow because of the Amazon-Orinoco River outflow (Lentz and Limeburner 1995; Hu et al. 2004; Rudzin et al. 2017).

The conservation of heat in the isothermal layer (total temperature tendency) is given by Eq. (6), where $T$ is the bulk isothermal layer and sea surface temperature, $u$ and $v$ are isothermal layer currents, $Q_{h}$ is total enthalpy flux, $h$ is ILD, $\Upsilon$ is a step function where $\Upsilon=0$ if entrainment velocity $w_{e}>0$, and $\Delta T$ is the difference between the thermocline $\left(T_{\mathrm{Tc}}\right)$ and isothermal layer temperatures. ILD is obtained from the SMARTS product subset to the time and location of each storm cluster:

$$
\frac{d T}{d t}=-u \frac{\partial T}{d x}-v \frac{\partial T}{d y}-\frac{Q_{h}}{\rho_{0} c_{p} h}-\Upsilon \frac{w_{e} \Delta T}{h} .
$$

Isothermal layer temperatures are obtained by assuming SST and isothermal layer temperatures are equal.
Thermocline temperature $T_{\mathrm{Tc}}$ is obtained using climatological data from World Ocean Atlas 2001 (Conkright et al. 2002), given that no in situ ocean data were obtained during these four storms near the clusters.

Horizontal temperature advection (HA) is described in the first and second terms on the right-hand side of Eq. (6), whereas surface and entrainment heat flux (SF and EF, respectively) are the third and fourth terms, respectively. The Kraus and Turner (1967) entrainment velocity scheme is used to infer $w_{e}[\mathrm{Eq}$. (7)] for the EF term in Eq. (6) since the upper-ocean response within the inertial period ( $\sim 48 \mathrm{~h}$ for the area of study) may be described by primarily instantaneous wind erosion. Entrainment velocity was evaluated using the following equation:

$$
w_{e}=\frac{\left(\tau / \rho_{0}\right)^{3 / 2}}{g^{\prime} h}+\frac{Q_{h}}{\rho_{0} c_{p} \Delta T} .
$$

Equation (7) accounts for density differences due to both temperature and salinity. Variables in Eq. (7) are defined above from Eq. (6), except for $\tau$, momentum flux, which is calculated from dropsondes. Reduced 

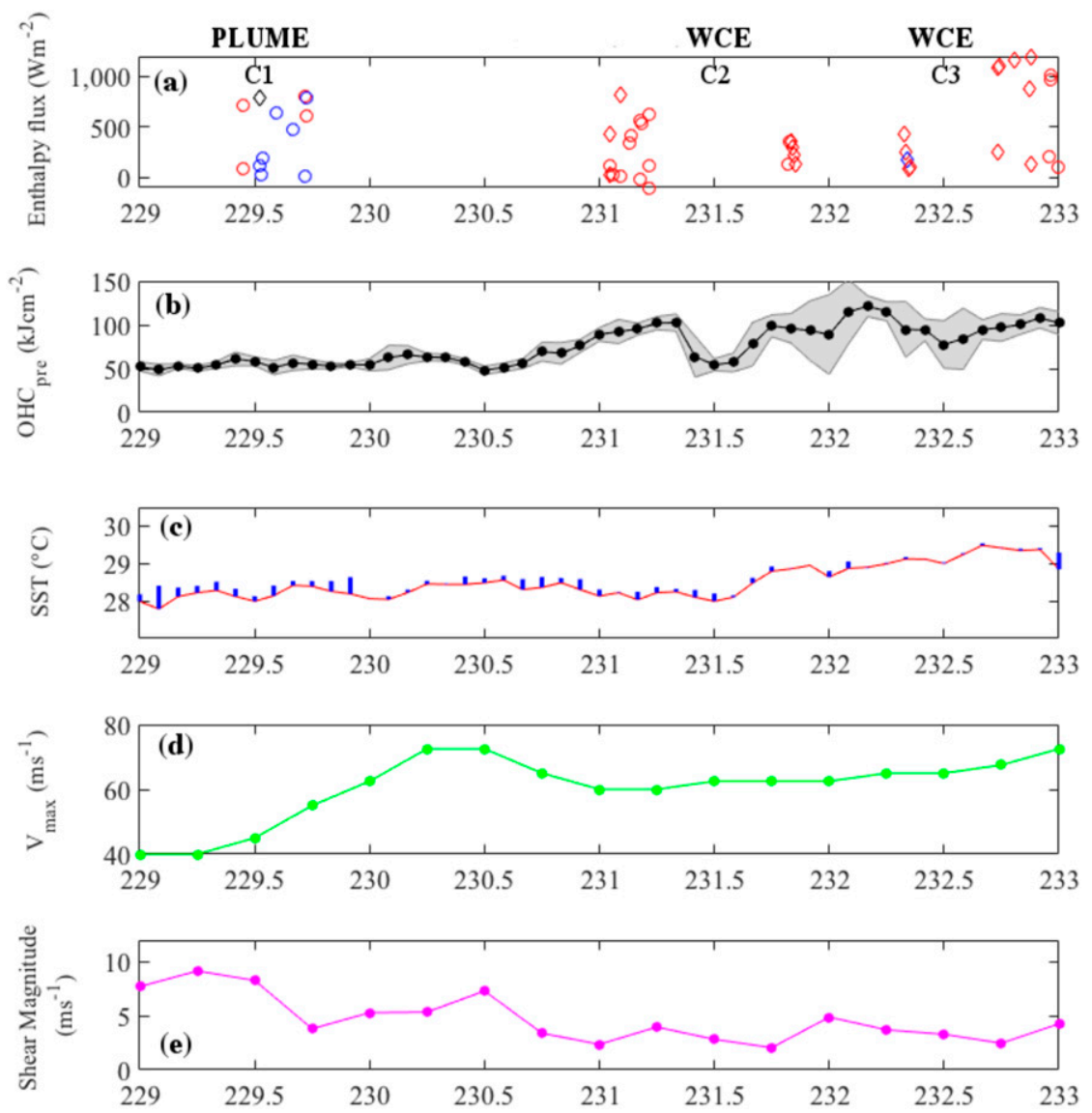

FIG. 6. As in Fig. 4, but for Hurricane Dean (2007).

gravity is defined as $g^{\prime}=\left(\rho_{\mathrm{Tc}}-\rho_{\mathrm{IL}}\right) / \rho_{0}$, where $\rho_{\mathrm{IL}}$, isothermal layer density, is estimated with World Ocean Atlas 2001 climatological salinity (Conkright et al. 2002) for the cluster location, and a uniform isothermal layer temperature profile is assumed from satellite SST. Total temperature tendency [Eq. (6)] is directly evaluated using 1-day satellite SST differences ( $\Delta$ SSTsat; Fig. 8).

Since no subsurface current measurements exist during these storms to retrieve isothermal layer currents for the HA term, the isothermal layer current is parameterized using a hurricane-forced ocean mixed layer scaling velocity from Price (1983). However, this term is revised from Price (1983), such that both the geostrophic and ageostrophic flow that occur within the hurricane-influenced ocean environment are accounted for. The $u$ and $v$ components of this parametric velocity are

$$
u_{\mathrm{IL}}=\frac{\left(f+\frac{\zeta_{g}}{2}\right) R_{\max }}{U_{h}}\left[\frac{\tau_{x}}{\left(f+\frac{\zeta_{g}}{2}\right) \rho_{0} h}-v_{g}\right],
$$

$$
v_{\mathrm{IL}}=\frac{\left(f+\frac{\zeta_{g}}{2}\right) R_{\max }}{U_{h}}\left[\frac{\tau_{y}}{\left(f+\frac{\zeta_{g}}{2}\right) \rho_{0} h}+u_{g}\right],
$$

where $U_{h}$ is storm translation speed, $u_{g}$ and $v_{g}$ are satellite-derived geostrophic $u$ - and $v$-velocity component fields, $\zeta_{g}$ is the background geostrophic vorticity field estimated from $u_{g}$ and $v_{g}$, and $\tau_{x}$ and $\tau_{y}$ are the $x$ and $y$ components of wind stress estimated from $\mathrm{H}^{*}$ wind fields (Powell et al. 1998). The derivation of these velocity components is found in appendix B. These velocity components in addition to the HA term are estimated at each grid point within the cluster domain.

This parametric velocity was tested for the case of Hurricane Lili (2002) in the Gulf of Mexico inside the Loop Current and in the background Gulf Common Water to assess its ability to capture the main upperocean current processes (appendix B). The comparison illustrates that the parametric velocity does fairly well at estimating both the direction of the isothermal layer current and the magnitude. Current magnitude is within 

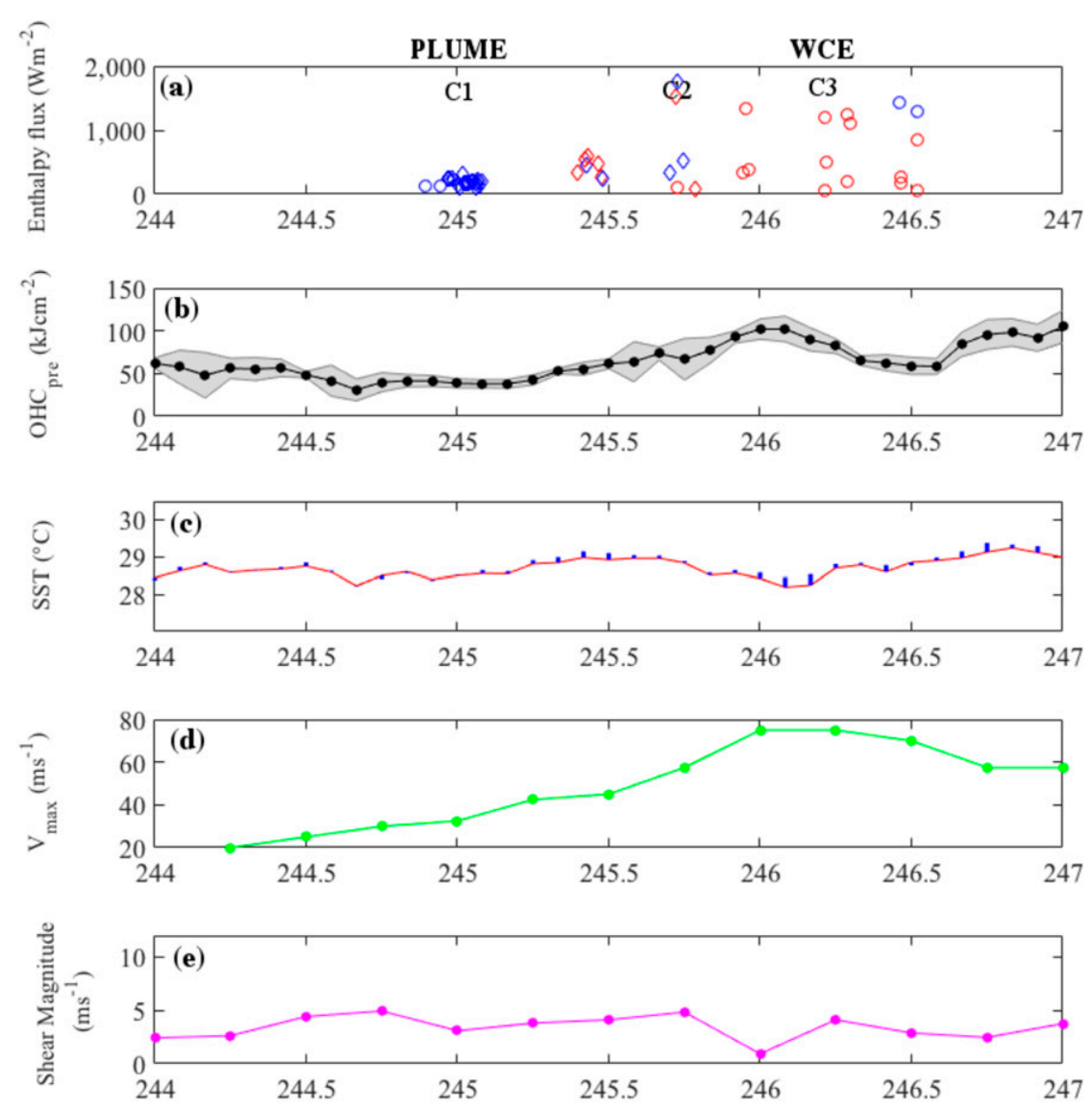

FIG. 7. As in Fig. 4, but for Hurricane Felix (2007).

$0.01 \mathrm{~cm} \mathrm{~s}^{-1}\left(\mathbf{V}_{\text {axcp }}=0.07 \mathrm{~cm} \mathrm{~s}^{-1}, \mathbf{V}_{\text {param }}=0.08 \mathrm{~cm} \mathrm{~s}^{-1}\right)$ in regions of low geostrophic current and/or background vorticity $\left(\sim 10^{-5} \mathrm{~s}^{-1}\right.$; Gulf Common Water) and is underpredicted $\left(\mathbf{V}_{\text {axcp }}=0.5 \mathrm{~cm} \mathrm{~s}^{-1}, \mathbf{V}_{\text {param }}=0.1 \mathrm{~cm} \mathrm{~s}^{-1}\right)$ in areas that have higher geostrophic currents and/or background vorticity $\left(\sim 10^{-4} \mathrm{~s}^{-1}\right.$; Loop Current; appendix B). Nonetheless, the parametric velocity captures the main first-order current processes occurring in highervorticity environments under TC wind forcing, such that both parametric velocity magnitude and observed current are the same order.

Total temperature tendency [Eq. (6)] is estimated at each grid point (0.125 Rmax) for a cluster domain (out to $5 \mathrm{Rmax}$ ) for only the storm-forced time period $(d t)$ and then spatially averaged (cluster averaged) over the cluster domain to obtain the results in Fig. 8. The time period $d t$ (in units of $n \mathrm{~h}^{-1}$ ) is calculated using $U_{h}$ and Rmax and is equivalent to the time for a storm to pass over the cluster domain. This time varies for each cluster and is broken down in appendix $\mathrm{C}$.

Cluster-averaged $d T / d t$ over the PLUME for each storm is within $0.4^{\circ} \mathrm{C}$ relative to $\Delta \mathrm{SST}_{\text {sat }} / \Delta t$ (GHRSST SST analysis error; JPL MUR MEaSUREs Project 2010;
Fig. 8) with all estimates within $1 / 10^{\circ}$ except during Hurricane Dean (Fig. 8c). Mean isothermal layer warming is prevalent in this cluster based on satellite estimates, which suggests second-order processes such as warm water advection, upwelling of inversions in barrier layer environments (Mignot et al. 2012), or poststorm surface warming (insolation) may have occurred during this time.

Our results suggest that $\mathrm{SF}$ is the largest contributor within the isothermal layer heat budget in the PLUME, whereas EF is secondary, and HA has minimal impact (approximately 69\%, 30\%, and 1\%, respectively; Fig. 8). The small values of HA do not necessarily imply that horizontal velocities are small, but rather that most water that is horizontally advected in is advected out (nearly horizontally nondivergent). EF has been found in previous studies to be the dominant cooling process within the isothermal layer during the TC passage (Jacob et al. 2000; Shay and Uhlhorn 2008). However, Jacob et al.'s (2000) study was conducted in the Gulf of Mexico (GoM) where upper-ocean stratification is much weaker than in the Caribbean Sea; reduced gravity $\left(g^{\prime} ; 1-2.5 \times 10^{-2} \mathrm{~m} \mathrm{~s}^{-2}\right.$; Shay and Uhlhorn 2008) in 
(a) Ivan C1

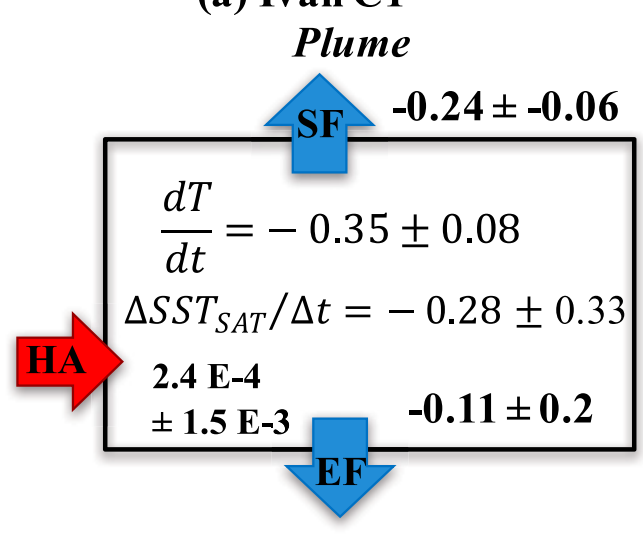

(c) Dean C1

Plume

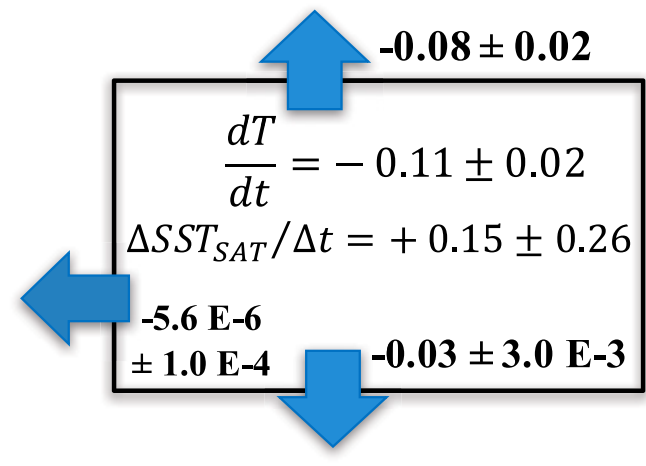

(b) Emily C1

Plume

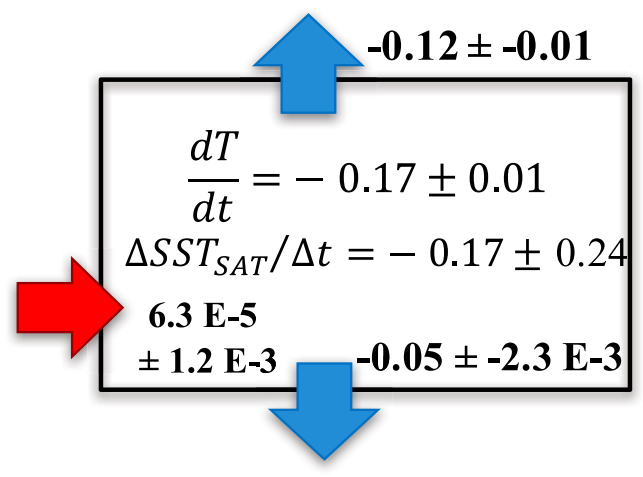

(d) Felix C1

Plume

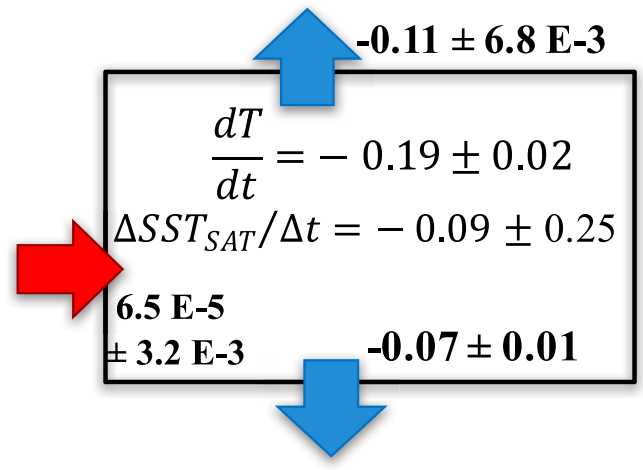

FIG. 8. Schematic of isothermal heat budget illustrating its horizontal and vertical components. Units for each term are ${ }^{\circ} \mathrm{C} n \mathrm{~h}^{-1}$, where $n \mathrm{~h}^{-1}$ (dt time units) for heat budget terms are listed in appendix C. (a) Acronyms that correspond to each term in the heat budget: $\mathrm{HA}\left({ }^{\circ} \mathrm{C} n \mathrm{~h}^{-1}\right), \mathrm{SF}\left({ }^{\circ} \mathrm{C} n \mathrm{~h}^{-1}\right)$, and $\mathrm{EF}\left({ }^{\circ} \mathrm{C} n \mathrm{~h}^{-1}\right)$. Cluster-averaged values \pm 1 std dev for each term, in addition to total temperature tendency $\left(d T / d t ;{ }^{\circ} \mathrm{C} n \mathrm{~h}^{-1}\right)$ as defined in Eq. (6), are listed next to the respective process that they represent. Blue-shaded processes are cooling processes, whereas red arrows represent warming processes. Note that $d t$ for $\Delta$ SSTsat is $24 \mathrm{~h}$ since satellite data are a daily product.

the GoM is less than half of values for these clusters (4.7-5.3 $\left.\times 10^{-2} \mathrm{~ms}^{-2}\right)$. Therefore, entrainment velocities (and EF) are less in the Caribbean Sea, compared to the GoM for a similar storm, because of the Caribbean Sea's upper-ocean density structure. These results substantiate those from section $4 \mathrm{a}$, such that reduced SST cooling in the PLUME is a result of the upperocean salinity stratification induced by river outflow, aiding in the excitement of air-sea fluxes in this region. Furthermore, EF in the PLUME is the same order as that in the WCE regimes (Ivan: $-0.15^{\circ} \pm 0.01^{\circ} \mathrm{C} n \mathrm{~h}^{-1}$,

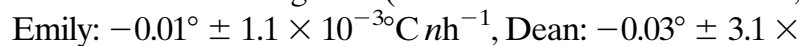
$10^{-3 \circ} \mathrm{C} n \mathrm{~h}^{-1}$, Felix: $-0.06^{\circ} \pm 0.01^{\circ} \mathrm{C} n \mathrm{~h}^{-1}$ ), suggesting that reduced EF in the PLUME from weaker wind forcing is not necessarily the reason for less SST cooling. These observational findings build upon idealized model findings by Rudzin et al. (2018) that also indicate that the rate of SST cooling is reduced in river plume waters when there is increased density stratification.

\section{c. Air-sea interaction and TC intensity change}

As stated previously, Emily, Dean, and Felix underwent RI while encountering the Amazon-Orinoco River plume, whereas Ivan steadily intensified (Figs. 1$2,4 d-7 d$ over the first day of year). While there are certain limitations in this study that prevent an in-depth investigation of the mechanisms or inhibition of RI for these cases (e.g., lack of high-resolution data), atmospheric parameters can be assessed to examine if these intensification scenarios may have been encouraged by favorable atmospheric conditions, regardless of ocean conditions. Deep-layer wind shear $(850-200 \mathrm{hPa})$ and equivalent potential temperature $\left(\theta_{E}\right.$; Bolton 1980) in the lower $100 \mathrm{hPa}$ are assessed for these storms' case to 
TABLE 3. Mean and $1 \mathrm{std}$ dev of PLUME and WCE dropsonde estimations (for dropsondes within 2 Rmax) of mean $\theta_{E}$ in the lowest $100 \mathrm{hPa}$ of the atmosphere. Parameter $\theta_{E}$ is estimated based on Bolton (1980). All PLUME dropsondes are within C1, whereas WCE dropsondes are within the cluster indicated next to values. Cluster time/location is indicated in table and can be visualized in Figs. 4a-7a.

\begin{tabular}{lllll}
\hline \hline \multicolumn{1}{c}{ Storm } & \multicolumn{1}{c}{ Ivan } & \multicolumn{1}{c}{ Emily } & \multicolumn{1}{c}{ Dean } & Felix \\
\hline PLUME $\theta_{E}(\mathrm{~K})$ & $357.1 \pm 5.1$ & $354.8 \pm 6.3$ & $362.0 \pm 4.6$ & $355.0 \pm 1.8$ \\
WCE $\theta_{E}(\mathrm{~K})$ & $365.7 \pm 11.3(\mathrm{C} 4)$ & $358.8 \pm 8.8(\mathrm{C} 3)$ & $373.6 \pm 7.3(\mathrm{C} 2)$ & $359.0 \pm 4.6(\mathrm{C} 2)$ \\
\hline
\end{tabular}

identify atmospheric favorability and to assess whether the ocean's role is negligible in these storm's RI and/or if the PLUME regimes' SST response and enthalpy fluxes may have encouraged RI. Values of deep-shear magnitude and direction are extracted from the Statistical Hurricane Intensity Prediction Scheme (SHIPS; DeMaria and Kaplan 1994) predictor files to assess upper- and midatmospheric favorability while these storms are over the PLUME regime.

Vertical wind shear is a well-known atmospheric parameter for RI (DeMaria 1996; Wong and Chan 2004; Paterson et al. 2005; Riemer et al. 2010; Onderlinde and Nolan 2017) such that it can inhibit TC deepening by destroying the upper-level warm core (Frank and Ritchie 2001) and ventilating midlevel dry air into the TC inner core (Simpson and Riehl 1958; Tang and Emanuel 2010). Shear also influences intensity via downdrafts of low $\theta_{E}$ into the boundary layer, inhibiting convection (Barnes et al. 1983; Riemer et al. 2010, 2013; Tang and Emanuel 2010, 2012; Riemer and Laliberté 2015). A few studies have indicated that surface enthalpy fluxes aid in the recovery of low-boundary layer $\theta_{E}$ from these downdrafts, and without sufficient surface enthalpy flux, a TC may weaken from insufficient convection (Cione et al. 2000; Molinari et al. 2013; Rogers et al. 2016; Zhang et al. 2013, 2017; Wadler et al. 2018). Hence, these two parameters, along with the previous analyses of SST response and enthalpy flux, may provide insight as to whether the atmosphere, ocean, or both were favorable in these RI scenarios.

Moderate deep vertical wind shear, defined as 4.5$11 \mathrm{~m} \mathrm{~s}^{-1}$ (Rios-Berrios and Torn 2017), occurred over the PLUME regime for Ivan, Emily, and Dean with 24-h mean values of $8.5,5.5$, and $6.8 \mathrm{~m} \mathrm{~s}^{-1}$, respectively (Figs. 4e-7e). Moderate shear also occurred over the WCE regime for Ivan and Emily with 24-h mean wind shear values of 8.2 and $8.0 \mathrm{~m} \mathrm{~s}^{-1}$ (Figs. 4e, 5e), respectively, whereas low shear occurred over the WCE regime during Dean (3.3 $\mathrm{m} \mathrm{s}^{-1}$; Fig. 6e). Conversely, 24-h mean wind shear over the PLUME and WCE regimes for Felix was roughly 3.5 and $3.9 \mathrm{~m} \mathrm{~s}^{-1}$ (Fig. 7e), respectively, favorable for intensification and RI (Kaplan and DeMaria 2003). Low shear values over the PLUME may better help explain Felix's RI in this region, as suggested by Hazelton and Hart (2013), whereas a combination of both low shear and high OHC over the central and western Caribbean Sea encouraged Felix's RI over this region (Hazelton and Hart 2013).

Statistically, wind shear has a negative effect on intensity change (DeMaria and Kaplan 1994; DeMaria 1996; Kaplan and DeMaria 2003; Kaplan et al. 2010) Yet, an increasing number of studies have found TC intensification occurs even under moderate shear values upward of $11 \mathrm{~m} \mathrm{~s}^{-1}$ (Molinari et al. 2004, 2006; Shelton and Molinari 2009; Molinari and Vollaro 2010; Nguyen and Molinari 2012; Tao and Zhang 2014). Nguyen and Molinari (2012) speculate that Hurricane Irene (2011) could overcome low $\theta_{E}$ downdrafts brought about by shear-induced vortex tilt because of large surface enthalpy fluxes from the warm Gulf Stream inducing intense diabatic heating and convection. Tao and Zhang (2014) found in simulations that higher SSTs lead to faster intensification rates and smaller tilt magnitude from stronger convection under moderate shear conditions. Since this mechanism has been documented in several studies, is it possible that surface enthalpy fluxes over the PLUME, aided by reduced SST cooling, were high enough to increase $\theta_{E}$ in the boundary layer and overcome the negative affects produced by moderate shear? Mean $\theta_{E}$ in the lower $100 \mathrm{hPa}\left(\right.$ called $\theta_{E M}$ ) from dropsondes over the PLUME regime is estimated to assess if this theory is possibly true. Measurements are azimuthally averaged rather than separated into vertical shear-referenced coordinates, given that the sparsity of data in each shear quadrant results in less robust findings. Values of $\theta_{E M}$ within 2 Rmax in the PLUME regime are within the lower range of $\theta_{E M}$ values that are within the WCE regime (Table 3), indicating the PLUME has similar warm, moist boundary layer conditions that we expect over a deep thermal ocean regime. Values within the PLUME are also comparable to those estimated when Hurricane Earl (2010) underwent intensification $\left(\theta_{E} \sim 360 \mathrm{~K}\right.$; Jaimes et al. 2015), those inside 2 Rmax when Hurricane Edouard (2014) underwent intensification $\left(\theta_{E} \sim 355-365 \mathrm{~K}\right.$; Zhang et al. 2017), and those within the inner core of a moderately sheared $\left(7.5 \mathrm{~m} \mathrm{~s}^{-1}\right)$ intensifying vortex simulated by Tao and Zhang $\left(2014 ; \theta_{E} \sim 345-355 \mathrm{~K}\right.$ for a warm, moist boundary layer and $\theta_{E} \sim 340-350 \mathrm{~K}$ for warm, dry boundary layer). 


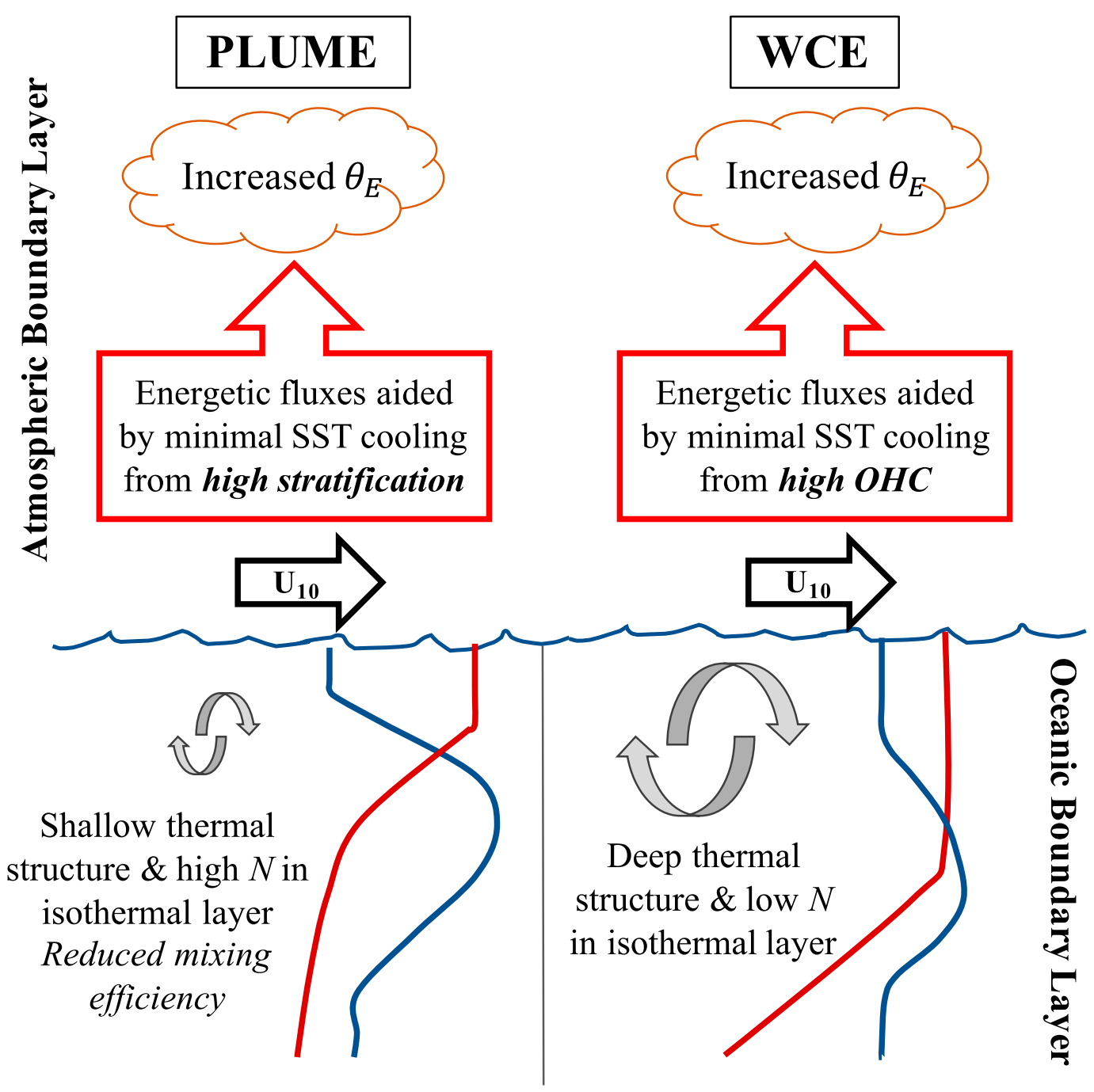

FIG. 9. A conceptual model of air-sea interaction for the two ocean regimes presented. Red and blue lines are oceanic temperature and salinity profiles, respectively. Gray arrows represent ocean mixing. Black arrow represents wind forcing.

These results, along with previous analyses, indicate increased plausibility that reduced SST cooling and sustained enthalpy transfer over the PLUME regime helped to increase $\theta_{E}$ to a point that is similar to the WCE regime and that has been shown in literature to induce TC intensification. Using these parameters, we speculate that reduced SST cooling and sustained enthalpy flux in the PLUME may have resulted in increased boundary layer moisture, which may have provided enough atmospheric instability to overcome the moderate wind shear environment over the PLUME region, as in other previous studies (Cione et al. 2000; Molinari et al. 2013; Rogers et al. 2016; Zhang et al. 2013, 2017). Hence, the oceanic conditions over the PLUME regime may have played a role in the intensification of Ivan and the RI of Emily and Dean, even under moderate wind shear conditions. Other possibilities for intensification and RI not considered include precipitation asymmetry (Zawislak et al. 2016; Rogers et al. 2016); environmental moisture (Ge et al. 2013; Tao and Zhang 2014); and the fact that boundary layer dynamics, such as dry, cool downdrafts (e.g., Cione et al. 2000, 2013), also help to increase air-sea fluxes.

\section{Conclusions and limitations}

The data and analyses presented within this study indicate that the Amazon-Orinoco River plume provides a positive air-sea feedback on passing TCs. This is in part due to the reduced SST cooling in the area from strong density stratification. Strong density stratification over this region imparted by the Amazon-Orinoco 

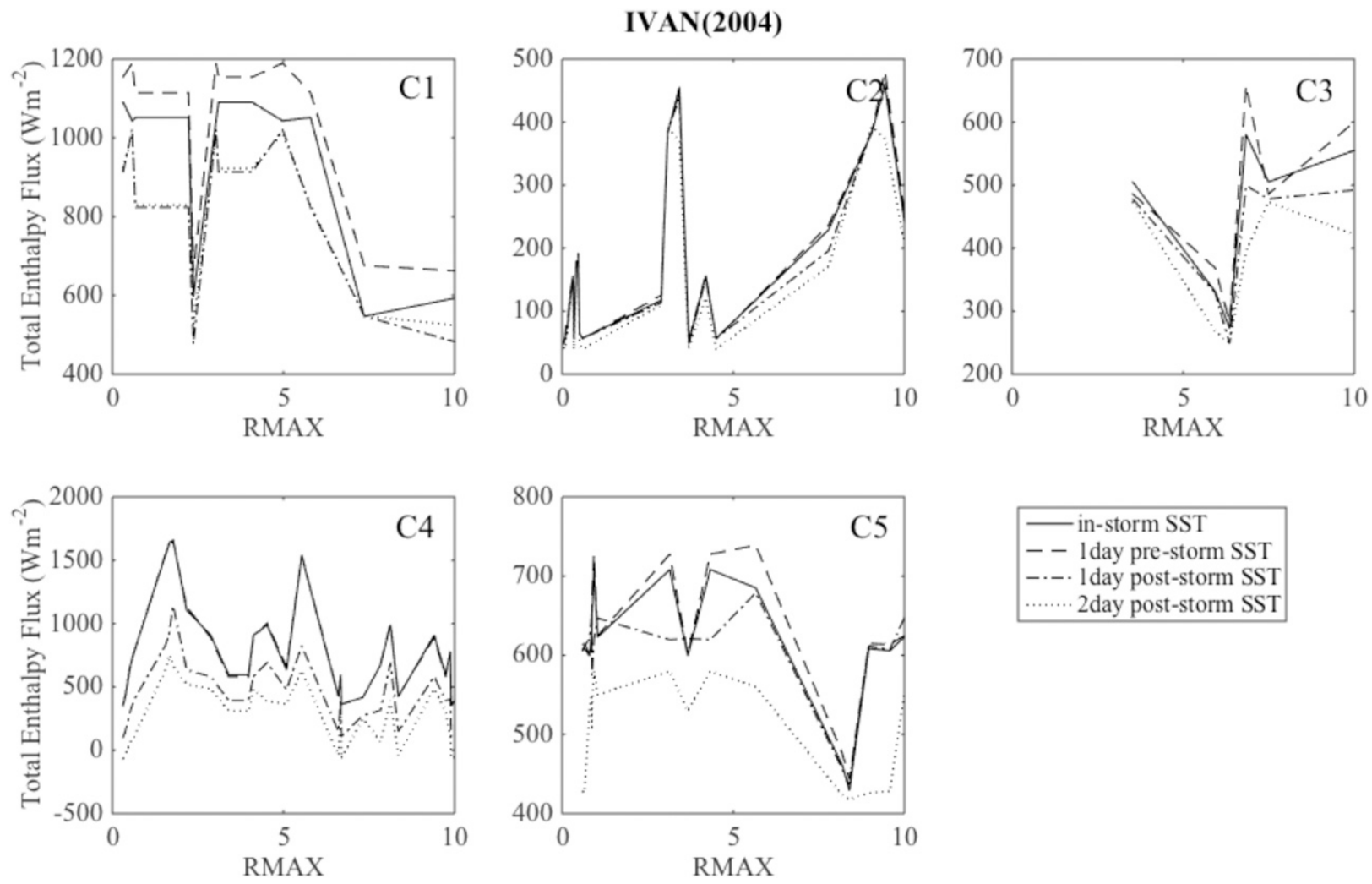

FIG. A1. Radial-averaged enthalpy flux calculated using SSTin (solid), 1-day-prestorm SST (dashed), 1-day-poststorm SST (dasheddotted), and 2-day-poststorm SST (dotted) for each cluster of Hurricane Ivan. All variables in this enthalpy flux calculation are consistent with in-storm conditions except for SST.

River plume is an aspect of ocean response that has not been previously thoroughly considered in the air-sea interaction process during TC passage in the Caribbean Sea.

Dropsonde data from four different storms that passed over both PLUME and WCE regimes revealed that enthalpy fluxes over the PLUME regime could be as energetic as those over the deep, warm waters within the WCE regime. Although OHC in the PLUME regime is much less than that within the WCE regime, SST cooling underneath each storm is comparable between the two regimes. Isothermal layer heat budgets within the PLUME regime show that entrainment heat flux, usually the dominant upper-ocean cooling process, was limited because of the increased salinity stratification in the PLUME regime. This finding agrees with those presented by Rudzin et al. (2018). Thus, increased salinity stratification in the PLUME regime essentially reduced the amount of SST cooling during storm passage, such that it was comparable to the WCE regime, and helped to sustain enthalpy fluxes into these storms. Consequently, sustained SSTs and enthalpy flux may have helped support warm, moist atmospheric boundary layer conditions (via $\theta_{E}$ ) and may have provided enough atmospheric instability to overcome moderate vertical wind shear and aid in these storms' intensification and $\mathrm{RI}$ in this region. A conceptual model of these findings is shown in Fig. 9. These findings are important since numerous studies have shown that areas of low $\mathrm{OHC}$ and shallow isothermal/mixed layers enhance SST cooling and provide a negative feedback on storm intensity. However, the increased salinity stratification in the AmazonOrinoco River plume improves ocean favorability and TC-ocean feedback.

From a TC forecasting perspective, Halliwell et al. (2011) stated that to correctly forecast intensity evolution within a TC, the ocean component of a coupled forecast model must accurately predict the pattern and rate of SST cooling. Furthermore, they found that the ocean model component is most sensitive to ocean initialization with regards to upper-ocean temperature and salinity profiles. However, the Caribbean Sea is one of the least-sampled ocean basins with respect to other ocean basins (Argo 2018). Thus, it is important to sample the Caribbean Sea's upper ocean, especially given the findings within this study, so that initial ocean state that goes into coupled forecast models is accurate to improve TC intensity forecasts. 
EMILY(2005)
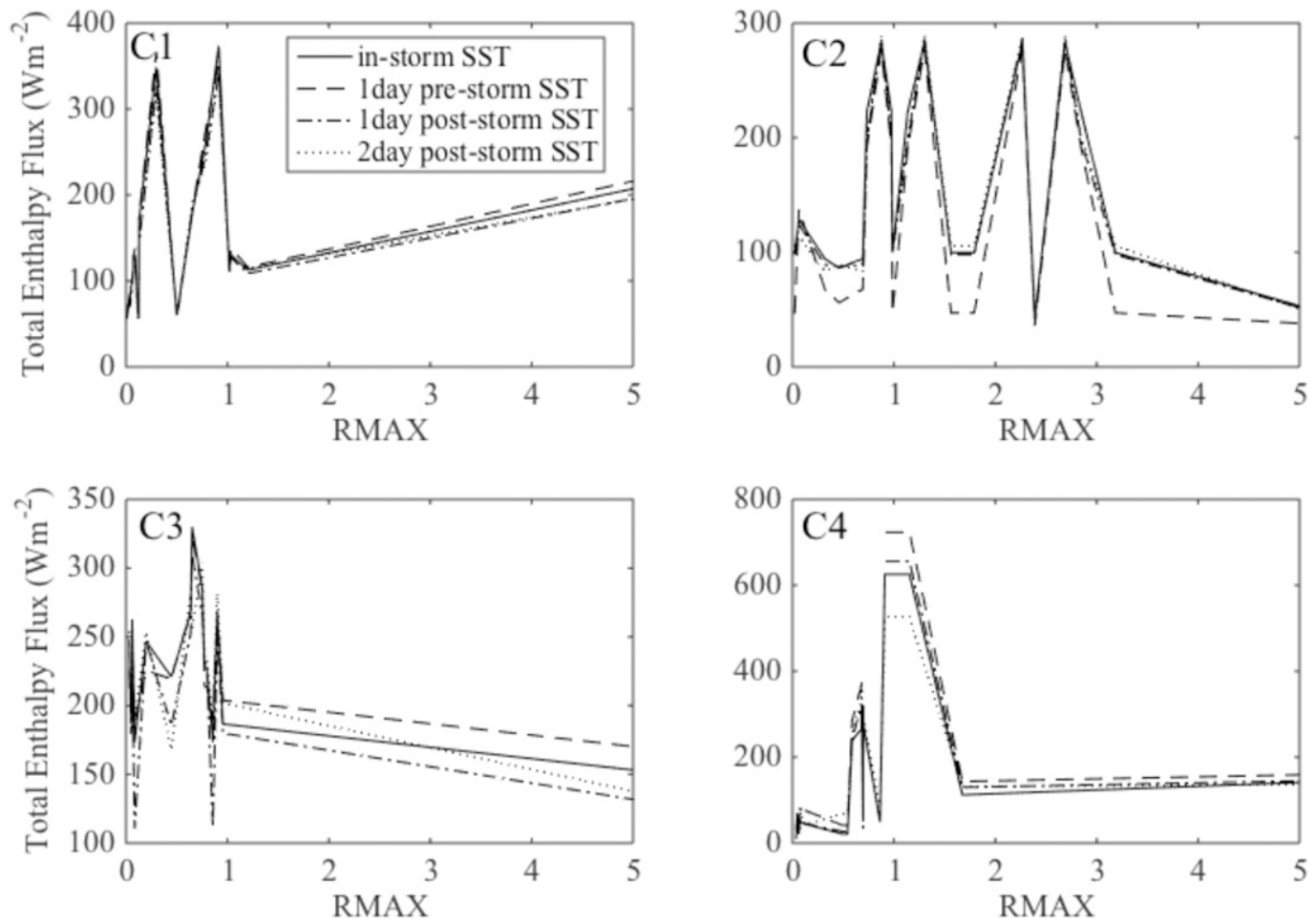

FIG. A2. As in Fig. A1, but for Hurricane Emily.

Since high-resolution (in time and space) in situ atmospheric and oceanic data were not available to conduct these analyses, many assumptions were made that create limitations on these conclusions. The limited spatial resolution of the dropsonde data along with the use of a daily satellite SST restricts the exactness of airsea flux estimates (assessment of error in appendix A). However, since the goal of the work was to understand how mesoscale oceanic thermal/haline structures influence SST and enthalpy flux response, we feel these methods are suitable for the goal of this work. Additionally, the lack of in situ ocean observations led to assumptions to estimate the isothermal layer heat budget. Nonetheless, satellite SST comparisons with the heat budget indicated the assumptions were reasonable. Last, atmospheric favorability was assumed from just two broadscale parameters, deep vertical wind shear and inner-core boundary layer $\theta_{E}$, whereas numerous studies have investigated many complex processes that determine atmospheric favorability with respect to TC intensification in literature. However, since the goal of the work focused on air-sea interaction, primarily the ocean's role, and not on the mechanism/inhibition of RI, we feel these parameters are appropriate to gauge broadscale atmospheric favorability.
Acknowledgments. The authors acknowledge the generous funding support by NASA (Grant NNX15AG43G). GPS-dropsonde data are provided courtesy of the NOAA/ AOML/Hurricane Research Division in Miami, Florida. The Group for High Resolution Sea Surface Temperature (GHRSST) Multiscale Ultra-High-Resolution (MUR) SST data were obtained from the NASA EOSDIS Physical Oceanography Distributed Active Archive Center (PO.DAAC) at the Jet Propulsion Laboratory, Pasadena, California (https://doi.org/10.5067/GHGMR-4FJ01). The authors also acknowledge the three reviewers and Josh Wadler (UM/RSMAS), whose reviews improved this manuscript. The authors also acknowledge Mark Powell (RMS-H*Wind), who generously provided highresolution $\mathrm{H}^{*}$ Wind data for this study.

\section{APPENDIX A}

\section{SST-Induced Error Estimates for Enthalpy Fluxes}

In-storm enthalpy flux presented within this manuscript for each cluster within each storm is compared to enthalpy fluxes estimated using prestorm and poststorm SST to identify if in-storm fluxes estimated from satellite SST are within the envelope of variability in the SST fields. 
DEAN(2007)
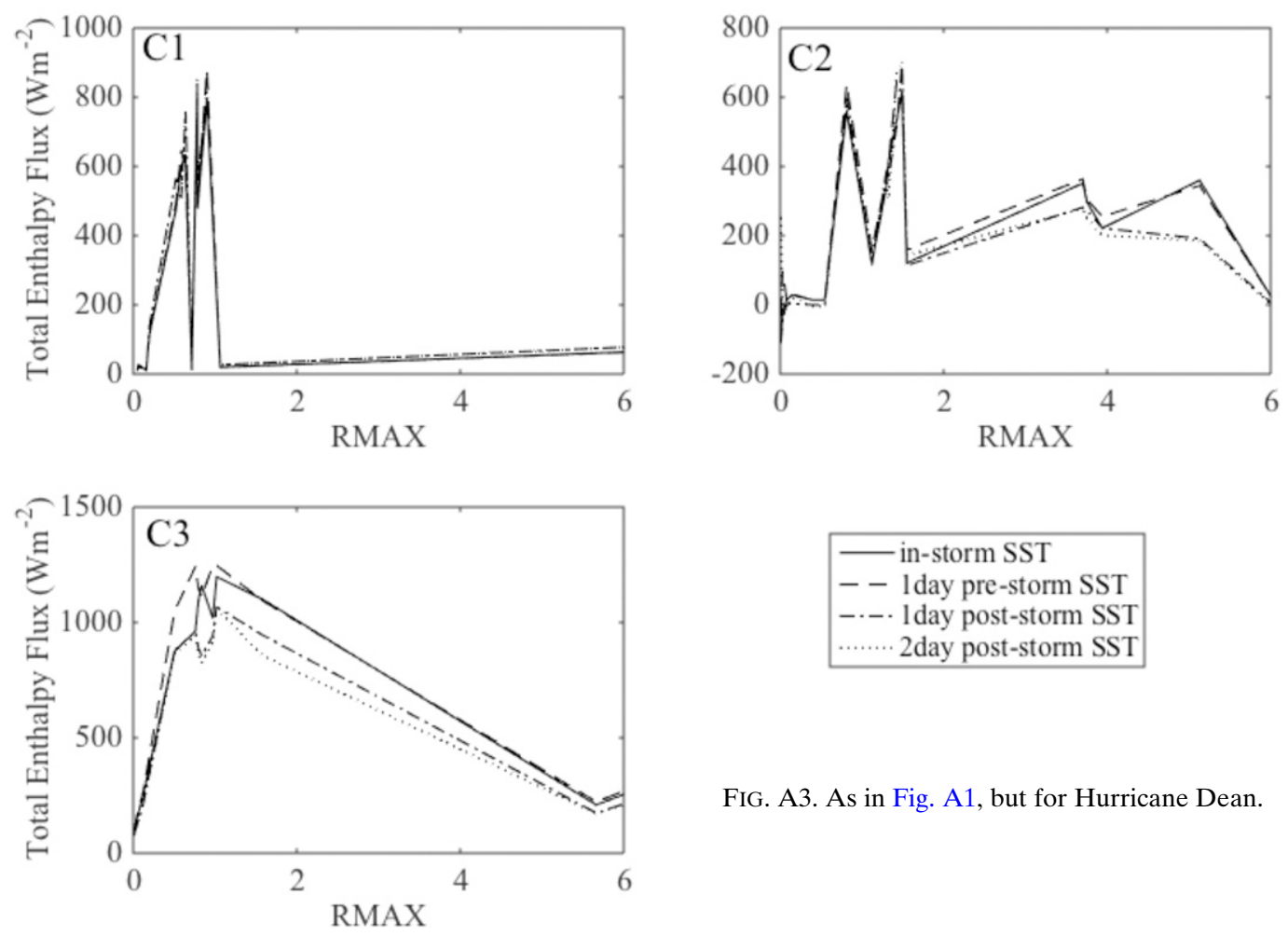

FIG. A3. As in Fig. A1, but for Hurricane Dean.

To further assess the limitations of using a satellite SST product, we looked at SST differences between the AXBT (data from Upper Ocean Dynamics Laboratory at RSMAS/UM) and the GHRSST SST daily satellite product for 415 AXBT deployments within Hurricanes Frances (2004), Jeanne (2004), Rita (2005), Dennis (2005), Gustav (2008), Ike (2008), and Danny (2009). GHRSST SST was collocated in space and time (same day as AXBT deployment) to estimate the difference shown here. These storms were chosen because of data availability, as there were no AXBT deployments for storms within the Caribbean Sea. Overall, approximately $42 \%$ of the 415 measurements are within $\pm 0.25^{\circ} \mathrm{C}$ difference, and $70 \%$ are within $\pm 0.5^{\circ} \mathrm{C}$ difference (Figures A1-A4).

\section{APPENDIX B}

\section{Derivation, Computation, and Comparison of Parametric Isothermal Layer Velocity}

a. Derivation of $U_{\mathrm{IL}}$ and $V_{\mathrm{IL}}$

From Price (1983),

$$
\begin{aligned}
& \frac{\partial}{\partial t} \sim U_{h} \frac{\partial}{\partial x}, \\
& \frac{\partial}{\partial t} \sim U_{h} \frac{\partial}{\partial y} .
\end{aligned}
$$

To incorporate the background flow in a hurricane environment, substitute (1) into Navier-Stokes equations, which results in

$$
\begin{aligned}
& U_{h} \frac{\partial u}{\partial x}=-\frac{1}{\rho_{0}} \frac{\partial p}{\partial x}+\frac{1}{\rho_{0}} \frac{\partial \tau_{x}}{\partial z}, \\
& U_{h} \frac{\partial v}{\partial y}=-\frac{1}{\rho_{0}} \frac{\partial p}{\partial y}+\frac{1}{\rho_{0}} \frac{\partial \tau_{y}}{\partial z} .
\end{aligned}
$$

Scaling (B2.1) and (B2.2) results in

$$
\begin{aligned}
& U_{h} \frac{u_{\mathrm{IL}}}{L}=-\frac{P}{\rho_{0} L}+\frac{\tau_{x}}{\rho_{0} h}, \\
& U_{h} \frac{v_{\mathrm{IL}}}{L}=-\frac{P}{\rho_{0} L}+\frac{\tau_{y}}{\rho_{0} h} .
\end{aligned}
$$

Assuming geostrophic, $P=f \rho_{0} L u_{g}$ and $P=f \rho_{0} L v_{g}$, substituting these into (B3.1) and (B3.2), respectively, leads to

$$
\begin{aligned}
& u_{\mathrm{IL}}=\frac{f L}{U_{h}}\left(-v_{g}+\frac{\tau_{x}}{f \rho_{0} h}\right), \\
& v_{\mathrm{IL}}=\frac{f L}{U_{h}}\left(u_{g}+\frac{\tau_{y}}{f \rho_{0} h}\right) .
\end{aligned}
$$


FELIX(2007)
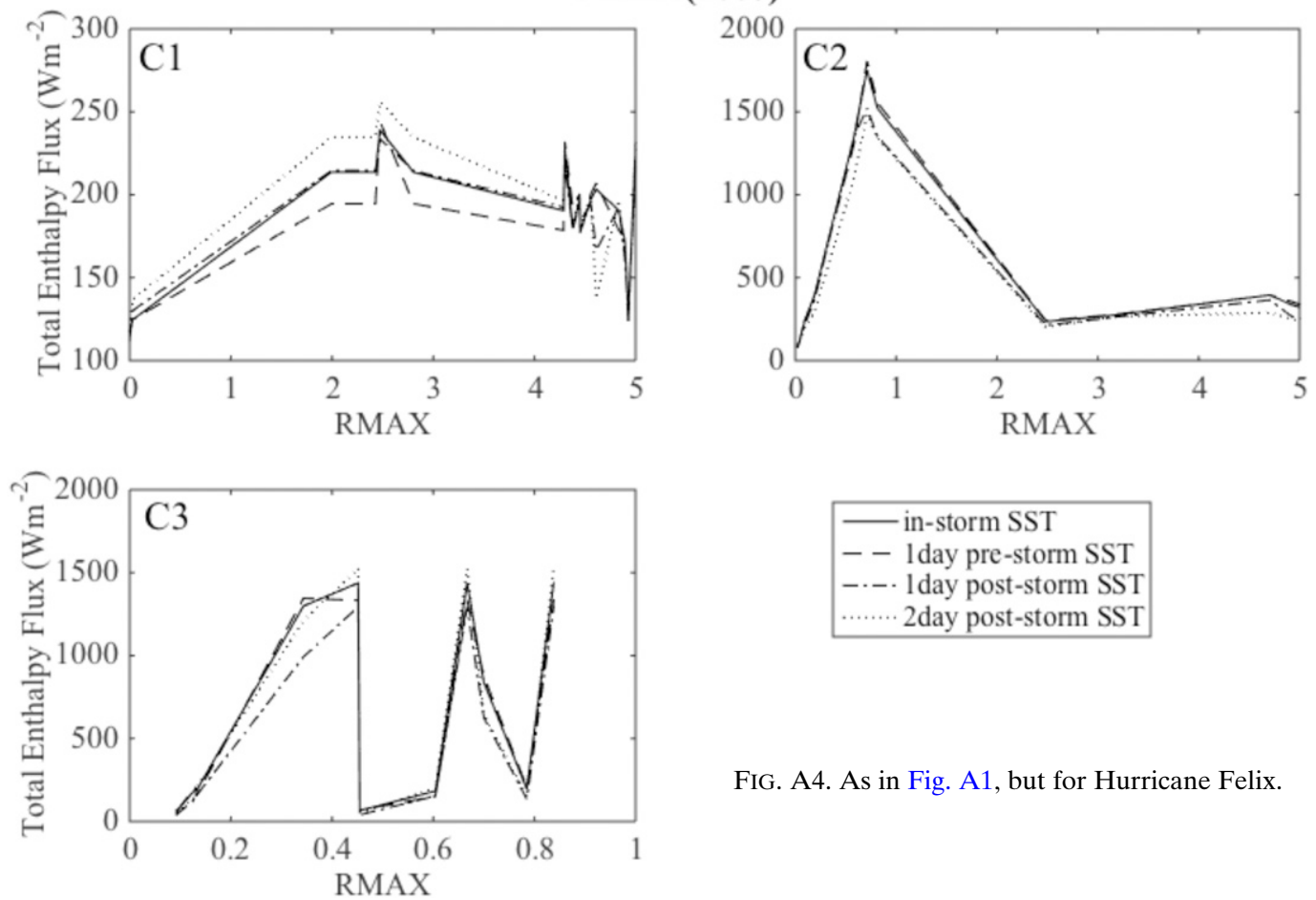

FIG. A4. As in Fig. A1, but for Hurricane Felix.

Substituting $f=f+\left(\zeta_{g} / 2\right)$ and $L=$ Rmax leads to the parametric velocity component equations shown in the main text.

\section{b. Parametric velocity estimation}

Estimated parametric velocities [Eqs. (8.1) and (8.2)] were compared to in situ isothermal layer velocities observed from an AXCP during Hurricane Lili (2002) in the Gulf of Mexico (Shay and Uhlhorn 2008). AXCP data were acquired from Uhlhorn and Shay (2012). Isothermal layer depth $h$, geostrophic current components $u_{g}$ and $v_{g}$, and geostrophic relative vorticity $\zeta_{g}$ are obtained from the SMARTS product (Meyers et al. 2014). Wind stress components $\tau_{x}$ and $\tau_{y}$ are estimated using $\mathrm{H}^{*}$ wind (Powell et al. 1998) wind field components and Powell et al. (2003) drag coefficients. Coriolis parameter, Rmax, and storm translation speed $U_{h}$ are obtained from NHC best track data (Landsea et al. 2004). The components are estimated for a $0.1^{\circ} \times 0.1^{\circ}$ box over the AXCP location and averaged over this box. Two AXCP locations are compared for this analysis: one deployed in the Gulf Common Water and one deployed in the Loop Current. AXCP velocities are averaged within the isothermal layer to obtain a velocity estimate to compare to the parametric velocities.

Using this method, it is found that current magnitude is within $0.01 \mathrm{~cm} \mathrm{~s}^{-1}\left(\mathbf{V}_{\text {axcp }}=0.07 \mathrm{~cm} \mathrm{~s}^{-1}, \mathbf{V}_{\text {param }}=\right.$ $0.08 \mathrm{~cm} \mathrm{~s}^{-1}$ ) in regions of low geostrophic current and/or

background vorticity $\left(\sim 10^{-5} \mathrm{~s}^{-1}\right.$; Gulf Common Water) and is underpredicted $\left(\mathbf{V}_{\text {axcp }}=0.5 \mathrm{~cm} \mathrm{~s}^{-1}, \mathbf{V}_{\text {param }}=\right.$ $\left.0.1 \mathrm{~cm} \mathrm{~s}^{-1}\right)$ in areas that have higher geostrophic currents and/or background vorticity $\left(\sim 10^{-4} \mathrm{~s}^{-1}\right.$; Loop Current; Fig. B1).

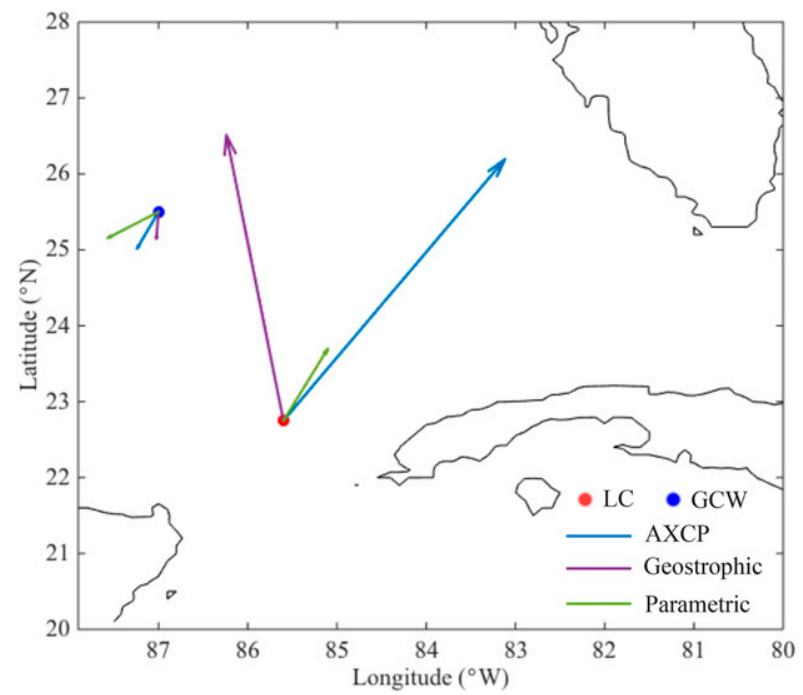

FIG. B1. Schematic comparison among AXCP, satellite-derived geostrophic velocity, and parametric isothermal layer velocity for the Loop Current (LC) and Gulf Common Water (GCW) during Hurricane Lili (2002). Note that the arrows are a schematic of the current magnitude, not actual current magnitude, because the magnitude and direction at scale are undistinguishable on this domain. 
TABLE C1. The time derivative $d t$ in hours for each cluster that was used to estimate the total temperature derivative $d T / d t$ in isothermal layer heat budget. Units of $n \mathrm{~h}^{-1}$ relate to the time for the storm to pass the area of the data cluster region. For example, the heat budget for Ivan $\mathrm{C} 1$ was estimated over a time range of $12.7 \mathrm{~h}$, the time for the storm to pass over the entire data cluster area. These numbers are based on $U_{h}$ and Rmax for the specific storm and cluster.

\begin{tabular}{cc}
\hline \hline Storm and cluster & $d t\left(n \mathrm{~h}^{-1}\right)$ \\
\hline Ivan C1 & 12.7 \\
Emily C1 & 11.2 \\
Dean C1 & 5.5 \\
Felix C1 & 15.4 \\
\hline
\end{tabular}

\section{APPENDIX C}

\section{Cluster Time Derivatives for Isothermal Layer Heat Budget}

Appendix C contains Table C1.

\section{REFERENCES}

Androulidakis, Y., V. Kourafalou, G. Halliwell, M. Le Hénaff, H. Kang, M. Mehari, and R. Atlas, 2016: Hurricane interaction with the upper ocean in the Amazon-Orinoco plume region. Ocean Dyn., 66, 1559-1588, https://doi.org/10.1007/ s10236-016-0997-0.

Argo, 2018: Argo float data and metadata from Global Data Assembly Centre (Argo GDAC). SEANOE, https://doi.org/ $10.17882 / 42182$.

Balaguru, K., P. Chang, R. Saravanan, L. R. Leung, Z. Xu, M. Li, and J.-S. Hsieh, 2012: Ocean barrier layers' effect on tropical cyclone intensification. Proc. Natl. Acad. Sci. USA, 109, 14 343-14347, https://doi.org/10.1073/pnas.1201364109.

Barnes, G. M., E. J. Zipser, D. Jorgensen, and F. Marks Jr., 1983: Mesoscale and convective structure of a hurricane rainband. J. Atmos. Sci., 40, 2125-2137, https://doi.org/10.1175/ 1520-0469(1983)040<2125:MACSOA > 2.0.CO;2.

Beven, J., 2008: Tropical cyclone report: Hurricane Felix. National Hurricane Center Rep. AL062007, 14 pp., https:// www.nhc.noaa.gov/data/tcr/AL062007_Felix.pdf.

Black, P. G., and Coauthors, 2007: Air-sea exchange in hurricanes: Synthesis of observations from the Coupled Boundary Layer Air-Sea Transfer Experiment. Bull. Amer. Meteor. Soc., 88, 357-374, https://doi.org/10.1175/BAMS-88-3-357.

Bolton, D., 1980: The computation of equivalent potential temperature. Mon. Wea. Rev., 108, 1046-1053, https://doi.org/ 10.1175/1520-0493(1980)108<1046:TCOEPT>2.0.CO;2.

Buck, A. L., 1981: New equations for computing vapor pressure and enhancement factor. J. Appl. Meteor., 20, 1527-1532, https://doi.org/10.1175/1520-0450(1981)020>1527:NEFCVP> 2.0.CO;2.

Cione, J. J., P. G. Black, and S. H. Houston, 2000: Surface observations in the hurricane environment. Mon. Wea. Rev., 128, 1550-1561, https://doi.org/10.1175/1520-0493(2000)128>1550: SOITHE $>2.0 . \mathrm{CO} ; 2 .</$ jrn

— E. A. Kalina, J. A. Zhang, and E. W. Uhlhorn, 2013: Observations of air-sea interaction and intensity change in hurricanes. Mon. Wea. Rev., 141, 2368-2382, https://doi.org/ 10.1175/MWR-D-12-00070.1.

Conkright, M. E., R. A. Locarnini, H. E. Garcia, T. D. O’Brien, T. P. Boyer, C. Stephens, and J. I. Antonov, 2002: World Ocean Atlas 2001: Objective analyses, data statistics, and figures. National Oceanographic Data Center Internal Rep. 17, 21 pp., https://repository.library.noaa.gov/view/noaa/1174/ noaa_1174_DS1.pdf?.

DeMaria, M., 1996: The effect of vertical shear on tropical cyclone intensity change. J. Atmos. Sci., 53, 2076-2088, https://doi.org/ 10.1175/1520-0469(1996)053<2076:TEOVSO > 2.0.CO;2.

_ diction Scheme (SHIPS) for the Atlantic Basin. Wea. Forecasting, 9, 209-220, https://doi.org/10.1175/1520-0434(1994) 009<0209:ASHIPS $>2.0$.CO;2.

Frank, W. M., and E. A. Ritchie, 2001: Effects of vertical wind shear on the intensity and structure of numerically simulated hurricanes. Mon. Wea. Rev., 129, 2249-2269, https://doi.org/ 10.1175/1520-0493(2001)129<2249:EOVWSO > 2.0.CO;2.

Franklin, J. L., 2008: Tropical cyclone report: Hurricane Dean. National Hurricane Center Rep. AL042007, 23 pp., https:// www.nhc.noaa.gov/data/tcr/AL042007_Dean.pdf.

— , and D. P. Brown, 2006: Tropical cyclone report: Hurricane Emily. National Hurricane Center Rep. AL052005, 18 pp., https://www.nhc.noaa.gov/data/tcr/AL052005_Emily.pdf.

Ge, X., T. Li, and M. Peng, 2013: Effects of vertical shears and midlevel dry air on tropical cyclone developments. J. Atmos. Sci., 70, 3859-3875, https://doi.org/10.1175/JAS-D-13-066.1.

Gentemann, C. L., and Coauthors, 2009: MISST: The Multi-Sensor Improved Sea Surface Temperature project. Oceanography, 22 (2), 76-87, https://doi.org/10.5670/oceanog.2009.40.

Grodsky, S. A., and Coauthors, 2012: Haline hurricane wake in the Amazon/Orinoco plume: AQUARIUS/SACD and SMOS observations. Geophys. Res. Lett., 39, L20603, https://doi.org/ 10.1029/2012GL053335.

Halliwell, G., L. K. Shay, J. K. Brewster, and W. J. Teague, 2011: Evaluation and sensitivity analysis of an ocean model response to Hurricane Ivan. Mon. Wea. Rev., 139, 921-945, https:// doi.org/10.1175/2010MWR3104.1.

Hazelton, A. T., and R. E. Hart, 2013: Hurricane eyewall slope as determined from airborne radar reflectivity data: Composites and case studies. Wea. Forecasting, 28, 368-386, https:// doi.org/10.1175/WAF-D-12-00037.1.

Hernandez, O., J. Jouanno, and F. Durand, 2016: Do the Amazon and Orinoco freshwater plumes really matter for hurricaneinduced ocean surface cooling? J. Geophys. Res. Oceans, 121, 2119-2141, https://doi.org/10.1002/2015JC011021.

Hock, T. F., and J. L. Franklin, 1999: The NCAR GPS dropwindsonde. Bull. Amer. Meteor. Soc., 80, 407-420, https://doi.org/ 10.1175/1520-0477(1999)080<0407:TNGD>2.0.CO;2.

Hu, C., E. T. Montgomery, R. W. Schmitt, and F. E. Müller-Karger, 2004: The dispersal of the Amazon and Orinoco River water in the tropical Atlantic and Caribbean Sea: Observation from space and S-PALACE floats. Deep-Sea Res. II, 51, 1151-1171, https://doi.org/10.1016/S0967-0645(04)00105-5.

Jacob, S. D., L. K. Shay, A. J. Mariano, and P. G. Black, 2000: The 3D oceanic mixed layer response to Hurricane Gilbert. J. Phys. Oceanogr., 30, 1407-1429, https://doi.org/10.1175/ 1520-0485(2000)030<1407:TOMLRT>2.0.CO;2.

Jaimes, B., and L. K. Shay, 2009: Mixed layer cooling in mesoscale oceanic eddies during Hurricanes Katrina and Rita. Mon. Wea. Rev., 137, 4188-4207, https://doi.org/10.1175/ 2009MWR2849.1. 
- , and -2010 : Near-inertial wave wake of Hurricanes Katrina and Rita over mesoscale oceanic eddies. J. Phys. Oceanogr., 40, 1320-1337, https://doi.org/10.1175/2010JPO4309.1.

— - - and E. W. Uhlhorn, 2015: Enthalpy and momentum fluxes during Hurricane Earl relative to underlying ocean features. Mon. Wea. Rev., 143, 111-131, https://doi.org/10.1175/ MWR-D-13-00277.1.

JPL MUR MEaSUREs Project, 2010: GHRSST level 4 MUR global foundation sea surface temperature analysis, version 2 . PO.DAAC, accessed 24 Jan 2019, https://doi.org/10.5067/ GHGMR-4FJ01.

Kaplan, J., and M. DeMaria, 2003: Large-scale characteristics of rapidly intensifying tropical cyclones in the North Atlantic basin. Wea. Forecasting, 18, 1093-1108, https://doi.org/10.1175/ 1520-0434(2003)018<1093:LCORIT>2.0.CO;2.

—,- , and J. A. Knaff, 2010: A revised tropical cyclone rapid intensification index for the Atlantic and eastern North Pacific basins. Wea. Forecasting, 25, 220-241, https://doi.org/10.1175/ 2009WAF2222280.1.

Kraus, E. B., and J. S. Turner, 1967: A one-dimensional model of the seasonal thermocline II. The general theory and its consequences. Tellus, 19, 98-106, https://doi.org/10.3402/ tellusa.v19i1.9753.

Landsea, C. W., and Coauthors, 2004: The Atlantic hurricane database re-analysis project: Documentation for the 1851-1910 alterations and additions to the HURDAT database. Hurricanes and Typhoons: Past, Present and Future, R. J. Murnane and K.-B. Liu, Eds., Columbia University Press, 177-221.

Leipper, D. F., and D. Volgenau, 1972: Hurricane heat potential of the Gulf of Mexico. J. Phys. Oceanogr., 2, 218-224, https://doi.org/10.1175/1520-0485(1972)002<0218:HHPOTG $>$ 2.0.CO;2.

Lentz, S. J., and R. Limeburner, 1995: The Amazon River plume during AMASSEDS: Spatial characteristics and salinity variability. J. Geophys. Res., 100, 2355-2375, https://doi.org/10.1029/ 94JC01411.

Lin, I.-I., C.-C. Wu, K. A. Emanuel, I.-H. Lee, C.-R. Wu, and I.-F. Pun, 2005: The interaction of Supertyphoon Maemi (2003) with a warm ocean eddy. Mon. Wea. Rev., 133, 2635-2649, https://doi.org/10.1175/MWR3005.1.

—, C.-H. Chen, I.-F. Pun, W. T. Liu, and C.-C. Wu, 2009: Warm ocean anomaly, air sea fluxes, and the rapid intensification of Tropical Cyclone Nargis (2008). Geophys. Res. Lett., 36, L03817, https://doi.org/10.1029/2008GL035815.

_ , and Coauthors, 2013: An ocean cooling potential intensity index for tropical cyclones. Geophys. Res. Lett., 40, 1878-1882, https://doi.org/10.1002/grl.50091.

Meyers, P. C., L. K. Shay, and J. K. Brewster, 2014: Development and analysis of the systematically merged Atlantic regional temperature and salinity climatology for oceanic heat content estimates. J. Atmos. Oceanic Technol., 31, 131-149, https:// doi.org/10.1175/JTECH-D-13-00100.1.

Mignot, J., C. de Boyer Montégut, A. Lazar, and S. Cravatte, 2007: Control of salinity on the mixed layer depth in the World Ocean: 2. Tropical areas. J. Geophys. Res., 112, C10010, https:// doi.org/10.1029/2006JC003954.

_ - A. Lazar, and M. Lacarra, 2012: On the formation of barrier layers and associated vertical temperature inversions: A focus on the northwestern tropical Atlantic. J. Geophys. Res., 117, C02010, https://doi.org/10.1029/2011JC007435.

Molinari, J., and D. Vollaro, 2010: Distribution of helicity, CAPE, and shear in tropical cyclones. J. Atmos. Sci., 67, 274-284, https://doi.org/10.1175/2009JAS3090.1.
,-- , and K. L. Corbosiero, 2004: Tropical cyclone formation in a sheared environment: A case study. J. Atmos. Sci., 61, 2493-2509, https://doi.org/10.1175/JAS3291.1.

—, P. Dodge, D. Vollaro, K. L. Corbosiero, and F. D. Marks Jr., 2006: Mesoscale aspects of the downshear reformation of a tropical cyclone. J. Atmos. Sci., 63, 341-354, https://doi.org/ 10.1175/JAS3591.1.

- J. Frank, and D. Vollaro, 2013: Convective bursts, downdraft cooling, and boundary layer recovery in a sheared tropical storm. Mon. Wea. Rev., 141, 1048-1060, https://doi.org/10.1175/ MWR-D-12-00135.1.

Neetu, S., M. Lengaigne, E. M. Vincent, J. Vialard, G. Madec, G. Samson, M. R. Ramesh Kumar, and F. Durand, 2012: Influence of upper-ocean stratification on tropical cycloneinduced surface cooling in the Bay of Bengal. J. Geophys. Res., 117, C12020, https://doi.org/10.1029/2012JC008433.

Nguyen, L. T., and J. Molinari, 2012: Rapid intensification of a sheared, fast-moving hurricane over the Gulf Stream. Mon. Wea. Rev., 140, 3361-3378, https://doi.org/10.1175/ MWR-D-11-00293.1.

Onderlinde, M. J., and D. S. Nolan, 2017: The tropical cyclone response to changing wind shear using the method of timevarying point-downscaling. J. Adv. Model. Earth Syst., 9, 908931, https://doi.org/10.1002/2016MS000796.

Pailler, K., B. Bourlès, and Y. Gouriou, 1999: The barrier layer in the western tropical Atlantic Ocean. Geophys. Res. Lett., 26, 2069-2072, https://doi.org/10.1029/1999GL900492.

Palmén, E., 1948: On the formation and structure of tropical hurricanes. Geophysika, 3, 26-38.

Paterson, L. A., B. N. Hanstrum, N. E. Davidson, and H. C. Weber, 2005: Influence of environmental vertical wind shear on the intensity of hurricane-strength tropical cyclones in the Australian region. Mon. Wea. Rev., 133, 3644-3660, https:// doi.org/10.1175/MWR3041.1.

Powell, M. D., S. H. Houston, L. R. Amat, and N. MorisseauLeroy, 1998: The HRD real-time hurricane wind analysis system. J. Wind Eng. Ind. Aerodyn., 77-78, 53-64, https://doi.org/ 10.1016/S0167-6105(98)00131-7.

-, P. J. Vickery, and T. A. Reinhold, 2003: Reduced drag coefficient for high wind speeds in tropical cyclones. Nature, $\mathbf{4 2 2}$, 279-283, https://doi.org/10.1038/nature01481.

Price, J. F., 1983: Internal wave wake of a moving storm. Part I: Scales, energy budget and observations. J. Phys. Oceanogr., 13, 949-965, https://doi.org/10.1175/1520-0485(1983)013<0949: IWWOAM $>2.0 . \mathrm{CO} ; 2$.

Reul, N., Y. Quilfen, B. Chapron, S. Fournier, V. Kudryavtsev, and R. Sabia, 2014: Multisensor observations of the AmazonOrinoco River plume interactions with hurricanes. J. Geophys. Res. Oceans, 119, 8271-8295, https://doi.org/10.1002/ 2014JC010107.

Riemer, M., and F. Laliberté, 2015: Secondary circulation of tropical cyclones in vertical wind shear: Lagrangian diagnostic and pathways of environmental interaction. J. Atmos. Sci., 72, 3517-3536, https://doi.org/10.1175/JAS-D-14-0350.1.

-, M. T. Montgomery, and M. E. Nicholls, 2010: A new paradigm for intensity modification of tropical cyclones: Thermodynamic impact of vertical wind shear on the inflow layer. Atmos. Chem. Phys., 10, 3163-3188, https://doi.org/ 10.5194/acp-10-3163-2010.

,-- , and - 2013: Further examination of the thermodynamic modification of the inflow layer of tropical cyclones by vertical wind shear. Atmos. Chem. Phys., 13, 327-346, https:// doi.org/10.5194/acp-13-327-2013. 
Rios-Berrios, R., and R. D. Torn, 2017: Climatological analysis of tropical cyclone intensity changes under moderate vertical wind shear. Mon. Wea. Rev., 145, 1717-1738, https://doi.org/ 10.1175/MWR-D-16-0350.1.

Rogers, R. F., J. Zhang, J. Zawislak, H. Jiang, G. R. Alvey III, E. J. Zipser, and S. N. Stevenson, 2016: Observations of the structure and evolution of Hurricane Edouard (2014) during intensity change. Part II: Kinematic structure and the distribution of deep convection. Mon. Wea. Rev., 144, 3355-3376, https://doi.org/10.1175/MWR-D-16-0017.1.

Rudzin, J. E., L. K. Shay, B. Jaimes, and J. K. Brewster, 2017: Upper ocean observations in eastern Caribbean Sea reveal barrier layer within a warm core eddy. J. Geophys. Res. Oceans, 122, 1057-1071, https://doi.org/10.1002/2016JC012339.

—_ - and W. E. Johns, 2018: The influence of the barrier layer on SST response during tropical cyclone wind forcing using idealized experiments. J. Phys. Oceanogr., 48, 1471-1478, https://doi.org/10.1175/JPO-D-17-0279.1.

Shay, L. K., and E. W. Uhlhorn, 2008: Loop Current response to Hurricanes Isidore and Lili. Mon. Wea. Rev., 136, 3248-3274, https://doi.org/10.1175/2007MWR2169.1.

_, G. J. Goni, and P. G. Black, 2000: Effects of a warm oceanic feature on Hurricane Opal. Mon. Wea. Rev., 128, 1366-1383, https://doi.org/10.1175/1520-0493(2000)128<1366:EOAWOF> 2.0.CO;2.

Shelton, K., and J. Molinari, 2009: Life of a six-hour hurricane. Mon. Wea. Rev., 137, 51-67, https://doi.org/10.1175/2008MWR2472.1.

Simpson, R., and R. Riehl, 1958: Mid-tropospheric ventilation as a constraint on hurricane development and maintenance. Tech. Conf. on Hurricanes, Miami Beach, FL, Amer. Meteor. Soc., D4-1-D4-10.

Sprintall, J., and M. J. Tomczak, 1992: Evidence of the barrier layer in the surface layer of the tropics. J. Geophys. Res., 97, 73057316, https://doi.org/10.1029/92JC00407.

Stewart, S. R., 2004: Tropical cyclone report: Hurricane Ivan. National Hurricane Center Re. AL092004, 44 pp., https:// www.nhc.noaa.gov/data/tcr/AL092004_Ivan.pdf.

Tang, B., and K. Emanuel, 2010: Midlevel ventilation's constraint on tropical cyclone intensity. J. Atmos. Sci., 67, 1817-1830, https://doi.org/10.1175/2010JAS3318.1.

$\longrightarrow$, and - 2012: Sensitivity of tropical cyclone intensity to ventilation in an axisymmetric model. J. Atmos. Sci., 69, 23942413, https://doi.org/10.1175/JAS-D-11-0232.1.

Tao, D., and F. Zhang, 2014: Effect of environmental shear, seasurface temperature, and ambient moisture on the formation and predictability of tropical cyclones: An ensemble-mean perspective. J. Adv. Model. Earth Syst., 6, 384-404, https:// doi.org/10.1002/2014MS000314.

Uhlhorn, E. W., and L. K. Shay, 2012: Loop current mixed layer energy response to Hurricane Lili (2002). Part I: Observations. J. Phys. Oceanogr., 42, 400-419, https://doi.org/10.1175/ JPO-D-11-096.1.

Vissa, N. K., A. N. V. Satyanarayana, and B. P. Kumar, 2013: Response of upper ocean and impact of barrier layer on Sidr cyclone induced sea surface cooling. Ocean Sci. J., 48, 279-288, https://doi.org/10.1007/s12601-013-0026-x.

Wadler, J. B., J. A. Zhang, B. Jaimes, and L. K. Shay, 2018: Downdrafts and the evolution of boundary layer thermodynamics in Hurricane Earl (2010) before and during rapid intensification. Mon. Wea. Rev., 146, 3545-3565, https://doi.org/ 10.1175/MWR-D-18-0090.1.

Wang, X., G. Han, Y. Qi, and W. Li, 2011: Impact of barrier layer on typhoon-induced sea surface cooling. Dyn. Atmos. Oceans, 52, 367-385, https://doi.org/10.1016/j.dynatmoce.2011.05.002.

Wong, M. L., and J. C. Chan, 2004: Tropical cyclone intensity in vertical wind shear. J. Atmos. Sci., 61, 1859-1876, https:// doi.org/10.1175/1520-0469(2004)061<1859:TCIIVW>2.0.CO;2.

Yan, Y., L. Li, and C. Wang, 2017: The effects of oceanic barrier layer on the upper ocean response to tropical cyclones. J. Geophys. Res. Oceans, 122, 4829-4844, https://doi.org/10.1002/ 2017JC012694.

Zawislak, J., H. Jiang, G. R. Alvey, E. J. Zipser, R. F. Rogers, J. A. Zhang, and S. N. Stevenson, 2016: Observations of the structure and evolution of Hurricane Edouard (2014) during intensity change. Part I: Relationship between the thermodynamic structure and precipitation. Mon. Wea. Rev., 144, 3333-3354, https://doi.org/10.1175/MWR-D-160018.1.

Zhang, J. A., P. G. Black, J. R. French, and W. M. Drennan, 2008: First direct measurements of enthalpy flux in the hurricane boundary layer: The CBLAST results. Geophys. Res. Lett., 35, L14813, https://doi.org/10.1029/2008GL034374.

_, R. F. Rogers, P. D. Reasor, E. W. Uhlhorn, and F. D. Marks Jr., 2013: Asymmetric hurricane boundary layer structure from dropsonde composites in relation to the environmental vertical wind shear. Mon. Wea. Rev., 141, 3968-3984, https:// doi.org/10.1175/MWR-D-12-00335.1.

_ J. J. Cione, E. A. Kalina, E. W. Uhlhorn, T. Hock, and J. A. Smith, 2017: Observations of infrared sea surface temperature and air-sea interaction in Hurricane Edouard (2014) using GPS dropsondes. J. Atmos. Oceanic Technol., 34, 1333-1349, https://doi.org/10.1175/JTECH-D-16-0211.1. 